Article

\title{
Environmental Risk and Risk of Resistance Selection Due to Antimicrobials' Occurrence in Two Polish Wastewater Treatment Plants and Receiving Surface Water
}

\author{
Joanna Giebułtowicz ${ }^{1}$, , Grzegorz Nałęcz-Jawecki ${ }^{2}$, Monika Harnisz ${ }^{3}{ }^{\circledR}$, Dawid Kucharski ${ }^{1}$, \\ Ewa Korzeniewska ${ }^{3}$ iD and Grażyna Płaza ${ }^{4, *}$ \\ 1 Department of Bioanalysis and Drugs Analysis, Faculty of Pharmacy, Medical University of Warsaw, \\ 1 Banacha, 02-097 Warszawa, Poland; jgiebultowicz@wum.edu.pl (J.G.); \\ dawid.kucharski@wum.edu.pl (D.K.) \\ 2 Department of Environmental Health Sciences, Faculty of Pharmacy, Medical University of Warsaw, \\ 1 Banacha, 02-097 Warszawa, Poland; grzegorz.nalecz-jawecki@wum.edu.pl \\ 3 Department of Environmental Microbiology, Faculty of Environmental Sciences, University of Warmia and \\ Mazury, 5 Oczapowskiego, 10-719 Olsztyn, Poland; monikah@uwm.edu.pl (M.H.); \\ ewa.korzeniewska@uwm.edu.pl (E.K.) \\ 4 Microbiology Unit, Institute for Ecology of Industrial Areas, 6 Kossutha, 40-844 Katowice, Poland \\ * Correspondence: g.plaza@ietu.pl; Tel.: +48 322546031
}

Academic Editors: Jolanta Kumirska and Teresa A. P. Rocha-Santos

Received: 21 February 2020; Accepted: 21 March 2020; Published: 24 March 2020

\begin{abstract}
In this study, a screening of 26 selected antimicrobials using liquid chromatography coupled to a tandem mass spectrometry method in two Polish wastewater treatment plants and their receiving surface waters was provided. The highest average concentrations of metronidazole $(7400 \mathrm{ng} / \mathrm{L})$, ciprofloxacin (4300 ng/L), vancomycin ( $3200 \mathrm{ng} / \mathrm{L})$, and sulfamethoxazole $(3000 \mathrm{ng} / \mathrm{L})$ were observed in influent of WWTP2. Ciprofloxacin and sulfamethoxazole were the most dominant antimicrobials in influent and effluent of both WWTPs. In the sludge samples the highest mean concentrations were found for ciprofloxacin (up to $28 \mu \mathrm{g} / \mathrm{g}$ ) and norfloxacin (up to $5.3 \mu \mathrm{g} / \mathrm{g}$ ). The removal efficiency of tested antimicrobials was found to be more than $50 \%$ for both WWTPs. However, the presence of antimicrobials influenced their concentrations in the receiving waters. The highest antimicrobial resistance risk was estimated in influent of WWTPs for azithromycin, ciprofloxacin, clarithromycin, metronidazole, and trimethoprim and in the sludge samples for the following antimicrobials: azithromycin, ciprofloxacin, clarithromycin, norfloxacin, trimethoprim, ofloxacin, and tetracycline. The high environmental risk for exposure to azithromycin, clarithromycin, and sulfamethoxazole to both cyanobacteria and eukaryotic species in effluents and/or receiving water was noted. Following the obtained results, we suggest extending the watch list of the Water Framework Directive for Union-wide monitoring with sulfamethoxazole.
\end{abstract}

Keywords: antibiotics; wastewater; sewage sludge; risk assessment; removal efficiency; LC-MS/MS analysis

\section{Introduction}

The fate of contaminants, particularly pharmaceutically active compounds (PhACs) in the environment is receiving considerable attention from researchers. PhACs appear as contaminants in wastewater, soil, surface and ground water, municipal sewage, and in the influents and effluents of wastewater treatment plants [1-3]. There are several sources of PhACs in the environment. The most 
important is human and veterinary medicine as well as plant agriculture. The main sources of aquatic contamination with human antimicrobials are wastewater treatment plants (WWTPs). The PhACs enter WWTPs along with wastewater from the disposal of unused or expired drugs in toilets. However, human excretion is considered to be the most important source. Generally, WWTPs are not designed to eliminate PhACs during the technological process, and a number of studies have shown the presence of different PhACs in both raw and treated sewage sludge and wastewater [4-8]. There is no data on either the removal efficiency or the concentration of antimicrobials in Polish WWTPs. The concentration of PhACs in the environment depends on the consumption of pharmaceuticals, which is country- and culture-specific, and their pharmacokinetics, and may considerably vary with seasons and physicochemical properties of these compounds, various process operating parameters of WWTPs, and bacterial community structure $[9,10]$. According to the European Centre for Disease Prevention, in 2018 the corresponding population-weighted mean consumption of antimicrobials (in defined daily dose (DDD) units per 1000 inhabitants per day) in European Union and European Economic Area countries was 18.4 DDD. In Poland the consumption rate was calculated as 23 DDD. Higher values were observed only for France (23.6 DDD), Greece (32.4 DDD), Romania (25.0 DDD) and Spain (24.3 DDD) [11].

Antimicrobials are one of the most extensively investigated PhACs. They belong to contaminants of emerging concern (CEC), which helps assess hazards to human health and ecosystems. They are one of the most popular pharmaceuticals used in veterinary care, farming, and medicine. According to the United States Geological Survey (USGS), CEC includes "any synthetic or naturally occurring chemical or any microorganism that is not commonly monitored in the environment, but has the potential to enter the environment and cause known or suspected adverse ecological and/or human health effects" [12].

WWTPs are not specifically designed for antimicrobial removal, and, consequently, these molecules are released directly into the receiving environment. An important issue is to identify the sources of antimicrobials in water and to assess their concentrations in surface, ground, and potable waters. The presence of antimicrobials in surface and ground waters, and even in drinking water, has been identified worldwide, for example in the UK [13], Italy [14], China [15], Australia [16], and the USA [17]. In our previous study, 20 of the 26 investigated antimicrobials up to a concentration of $1000 \mathrm{ng} / \mathrm{L}$ in the river water close to the effluent discharge from the main WWTP in Warsaw (Poland) were detected [18]. Although WWTPs are considered the main source of antimicrobials for surface waters, the current legislation at a European level does not contain an antimicrobial concentration requirement for discharge from WWTPs to receiving water. Antimicrobials have been determined in numerous WWTPs such as those in Germany [8,19], France [7], Croatia [20], Spain [21], China [22], Switzerland [23], Sweden [24], and Norway [25]. Given the number of scientific papers regarding the analysis of the antimicrobials' concentrations in European and global WWTPs, the knowledge of the occurrence of antimicrobials in Polish WWTPs is scare. Moreover, there are only scarce data on risk assessment on resistance selection and on environmental toxicity in WWTPs. To our best knowledge, no such data regarding sludge and sludge-affected soils exists.

The presence of the antimicrobials in the environment may pose an environmental risk. Environmental risk is defined as actual or potential threat of adverse effects on aquatic and/or terrestrial organisms. In the case of antimicrobials, the most endangered are prokaryotes, e.g., nitrification bacteria [26] or cyanobacteria [27]. Antimicrobials can also pose a risk of resistance selection. It is observed as preferential outgrowth of antimicrobial-resistant bacteria and changes in the antibiotic sensitivity of the entire microbial population in antimicrobial concentrations below the minimal inhibitory concentration. As a consequence, the resistant bacteria is able to survive in the presence of an antimicrobial in concentration that is usually sufficient to inhibit or kill microorganisms of the same species [28]. The antimicrobial-resistant genes can be transferred between distantly related bacterial species and to bacteria that colonize the human body and human pathogens [26]. The estimates 
suggest that 700,000 deaths occur every year because of antimicrobial resistance; moreover, by 2050, there might be 10 million deaths every year [29].

In this context, the aim of the study was to investigate the occurrence, abundance, and removal efficiency of the selected antimicrobials in two Polish wastewater treatment plants. The risk assessment approach based on environmental risk quotients (RQs) was also calculated to assess antimicrobial resistance risks and ecological environmental risk of antimicrobials to cyanobacteria and eukaryotic species. The antimicrobials were selected based on the sales data and occurrence of the antimicrobials in the environment in Europe. Additionally, the satisfactory performance of the analytical method was taken into account.

\section{Results}

\subsection{Predicted Concentrations of Antimicrobials in WWTPs}

According to sales data for 2018 (published by the Polish National Health Fund (NFZ)), among detected antimicrobials, the highest sale in Poland was noted for clarithromycin (up to $1509 \mathrm{~kg} / \mathrm{month}$ ), sulfamethoxazole (up to $1358 \mathrm{~kg} /$ month), ofloxacin (up to $829 \mathrm{~kg} /$ month), ciprofloxacin (up to $821 \mathrm{~kg} /$ month), and clindamycin (737 kg/month). We compared the predicted load of antimicrobials in the WWTP1 (PLoad) (Poland) with the load calculated based on the measured concentrations of the drugs in the influent (water phase) and in the primary sludge ( $\left.\operatorname{Load}_{W+S}\right)$ (Table A1, Online Resource). For most of the tested antimicrobials, the Load $_{\mathrm{W}+\mathrm{S}}$ to PLoad ratio was low (up to $20 \%$ ) because the high metabolism in the human body results in a lower level of parent compound, e.g., the biotransformation ratio of clindamycin is $85 \%$ [30]. Moreover, the measured load of fluoroquinolones (ciprofloxacin and norfloxacin) was very close to that of the predicted load, and unlike other antimicrobials that are primarily present in the water phase, ciprofloxacin and norfloxacin are distributed evenly between water and the primary sludge. For six antimicrobials (erythromycin, metronidazole, oxytetracycline, tetracycline, sulfathiazole, and vancomycin), the $\operatorname{Load}_{\mathrm{W}+\mathrm{S}}$ to PLoad ratio was very high and exceeded $1000 \%$ because of the low and very low predicted load value. Note that almost all antimicrobials in Poland are available by prescription and most of them are reimbursed; however, some, such as vancomycin, are primarily used in hospitals, while tetracyclines (oxytetracycline and tetracycline) and sulfathiazole are primarily used in veterinary medicine and are not reported by NFZ.

\subsection{Antimicrobial Concentrations in Influents of WWTPs}

The concentrations of 26 antimicrobials in influents from WWTP1 and WWTP2 and receiving waterbodies are shown in Table 1 . The significant differences between the concentrations of antimicrobials in the samples collected in different sampling periods were observed. The differences were due to seasonal variations in antimicrobial use. According to National Health Fund (NFZ) database, in summer the consumption of antimicrobials was low (Table A1). In autumn and winter, the consumption increased significantly, probably due to numerous infections occurring each year in that period [31]. 
Table 1. Mean and standard deviation $(n=3)$ of the target antimicrobial concentrations $(\mathrm{ng} / \mathrm{L})$ in influent, effluent, and receiving water of two wastewater treatment plants (WWTPs) located in Poland at Silesian (WWTP1) and Warmian-Masurian Voivodship (WWTP2).

\begin{tabular}{|c|c|c|c|c|c|c|c|c|c|c|c|c|c|c|c|c|c|c|c|c|}
\hline & \multicolumn{2}{|c|}{$\begin{array}{l}\text { WWTP1 } \\
\text { Influent }\end{array}$} & \multicolumn{2}{|c|}{$\begin{array}{l}\text { WWTP1 } \\
\text { Effluent }\end{array}$} & \multicolumn{2}{|c|}{$\begin{array}{l}\text { WWTP1 } \\
\text { Leachate }\end{array}$} & \multicolumn{2}{|c|}{$\begin{array}{c}\text { River1 } \\
\text { Upstream }\end{array}$} & \multicolumn{2}{|c|}{$\begin{array}{c}\text { River1 } \\
\text { Downstream }\end{array}$} & \multicolumn{2}{|c|}{$\begin{array}{l}\text { WWTP2 } \\
\text { Influent }\end{array}$} & \multicolumn{2}{|c|}{$\begin{array}{l}\text { WWTP2 } \\
\text { Effluent }\end{array}$} & \multicolumn{2}{|c|}{$\begin{array}{c}\text { River2 } \\
\text { Upstream }\end{array}$} & \multicolumn{2}{|c|}{$\begin{array}{c}\text { River2 } \\
\text { Downstream }\end{array}$} & \multirow[t]{2}{*}{$\mathrm{MDL}^{1}$} & \multirow[t]{2}{*}{$\mathrm{MQL}^{1}$} \\
\hline & Mean & SD & Mean & SD & Mean & SD & Mean & SD & Mean & SD & Mean & SD & Mean & SD & Mean & SD & Mean & SD & & \\
\hline AZM & 87 & 71 & 230 & 110 & 320 & 290 & 25 & 15 & 441 & 249 & 360 & 450 & 650 & 680 & 5.2 & 2.7 & 36 & 21 & 10 & 33 \\
\hline CIP & 1260 & 680 & 184 & 72 & 890 & 410 & 108 & 33 & 95 & 4 & 4300 & 4300 & 312 & 73 & 12 & 12 & 182 & 182 & 2.4 & 8.1 \\
\hline CLR & 480 & 190 & 160 & 170 & 102 & 23 & 37 & 9 & 79 & 50 & 560 & 590 & 143 & 40 & 12.2 & 8.2 & 20.5 & 11.1 & 0.3 & 0.9 \\
\hline CLI & 134 & 87 & 166 & 60 & 73 & 37 & 78 & 46 & 134 & 3 & 106 & 51 & 290 & 200 & 2.3 & 1.1 & 25.4 & 3.5 & 2.9 & 9.5 \\
\hline ERY & 58 & 71 & 21 & 18 & 30 & 42 & 7 & 7 & 10 & 0 & 28 & 20 & 16 & 12 & \multicolumn{2}{|c|}{$<\mathrm{MDL}$} & \multicolumn{2}{|c|}{$<\mathrm{MDL}$} & 0.7 & 2.4 \\
\hline LCM & 20 & 15 & 48 & 52 & 24.7 & 7.8 & 3 & 3 & 9 & 4 & 102 & 46 & 56 & 19 & \multicolumn{2}{|c|}{$<\mathrm{MDL}$} & 4.0 & 1.4 & 1.4 & 4.7 \\
\hline MTZ & 250 & 160 & 69 & 82 & 11.1 & 8.4 & 9 & 3 & 21 & 11 & 7400 & 9600 & 88 & 41 & \multicolumn{2}{|c|}{$<\mathrm{MDL}$} & 9.4 & 3.1 & 2.4 & 7.9 \\
\hline NOR & 240 & 130 & 31 & 28 & 210 & 150 & 95 & 93 & \multicolumn{2}{|c|}{$<$ MDL } & 80 & 110 & 10 & 11 & \multicolumn{2}{|c|}{$<\mathrm{MDL}$} & \multicolumn{2}{|c|}{$<$ MDL } & 6.3 & 21 \\
\hline OFX & 135 & 35 & 26 & 14 & 200 & 91 & 32 & 18 & 4 & 4 & 195 & 21 & 40 & 11 & 8.4 & 0.5 & 31 & 23 & 1.4 & 4.6 \\
\hline OTC & 0.7 & 0.9 & 0.1 & 0.1 & 1.1 & 1.4 & \multicolumn{2}{|c|}{$<\mathrm{MDL}$} & 1 & 0 & \multicolumn{2}{|c|}{$<$ MDL } & \multicolumn{2}{|c|}{$<\mathrm{MDL}$} & \multirow{2}{*}{\multicolumn{2}{|c|}{$<$ MDL }} & \multicolumn{2}{|c|}{$<$ MDL } & 0.1 & 0.2 \\
\hline RIF & 5.2 & 3.3 & \multicolumn{2}{|c|}{$<$ MDL } & \multicolumn{2}{|c|}{$<\mathrm{MDL}$} & \multicolumn{2}{|c|}{$<\mathrm{MDL}$} & \multicolumn{2}{|c|}{$<\mathrm{MDL}$} & 5.3 & 3.4 & 2.9 & 2 & & & $<\mathrm{N}$ & & 2.9 & 9.6 \\
\hline ROX & 18 & 19 & 6.6 & 6.9 & 1.6 & 1.6 & 4 & 4 & 5 & 2 & 6.2 & 5.3 & 6.2 & 2.1 & \multicolumn{2}{|c|}{$<\mathrm{MDL}$} & $<\mathrm{N}$ & & 0.5 & 1.6 \\
\hline $\mathrm{SD}$ & $<\mathrm{M}$ & & 3.4 & 4.3 & 2.4 & 2.5 & & & & & $<\mathrm{M}$ & & $<\mathrm{M}$ & & $<\mathrm{N}$ & & $<\mathrm{N}$ & & 0.6 & 1.9 \\
\hline SDM & 4.1 & 3.2 & 3.4 & 3.5 & $<\mathrm{N}$ & & & & & & 8.9 & 7.2 & 4.9 & 3.6 & $<\mathrm{N}$ & & $<\mathrm{N}$ & & 1.8 & 6.1 \\
\hline SXT & 1300 & 460 & 630 & 220 & 480 & 630 & 644 & 41 & 451 & 95 & 3000 & 1900 & 770 & 280 & $<\mathrm{N}$ & & 76.1 & 4.6 & 5.9 & 19 \\
\hline ST & 94 & 46 & 21 & 14 & 136 & 54 & 7 & 6 & 29 & 19 & 180 & 110 & 36 & 16 & $<\mathrm{N}$ & & $<\mathrm{N}$ & & 2.4 & 8 \\
\hline TET & 190 & 190 & 39 & 55 & 180 & 170 & & & 0 & 0 & 210 & 160 & 61 & 48 & $<\mathrm{N}$ & & 7.2 & 6.4 & 0.2 & 0.7 \\
\hline TBZ & 18.4 & 2.8 & 22.3 & 4.5 & 18 & 11 & 12 & 7 & 16 & 0 & 11 & 2.8 & 25.5 & 3 & $<\mathrm{N}$ & & 4.3 & 2.1 & 2.8 & 9.4 \\
\hline TMP & 254 & 41 & 160 & 190 & 94 & 52 & 38 & 3 & 36 & 8 & 900 & 770 & 220 & 110 & 9.1 & 8.4 & 24.4 & 3.9 & 3 & 9.9 \\
\hline VAN & 350 & 390 & 114 & 60 & 840 & 220 & 27 & 23 & 62 & 8 & 3200 & 3600 & 162 & 62 & $<\mathrm{N}$ & & 10.7 & 3.2 & 15 & 50 \\
\hline
\end{tabular}

Presented MDLs and method quantitation limits (MQLs) were calculated for influents. The values for effluents are about two times lower and for surface water about four times lower.
Pats 
Nineteen and 18 out of 26 analyzed antimicrobials were detected in the wastewater from WWTP1 and WWTP2, respectively. In most cases, the antimicrobial levels were higher in wastewater of WWTP2 than in wastewater of WWTP1. The mean values of antimicrobials' concentration in analyzed samples ranged from $<$ MDL (method detection limit) to $7400 \mathrm{ng} / \mathrm{L}$. In influent from WWTP1, the average concentrations of two antimicrobials, i.e., ciprofloxacin and sulfamethoxazole, were higher than $1000 \mathrm{ng} / \mathrm{L}$ and concentrations of 10 antimicrobials was higher than $100 \mathrm{ng} / \mathrm{L}$. While in influent from WWTP2, the concentration of four antimicrobials, i.e., ciprofloxacin, metronidazole, sulfamethoxazole, and vancomycin, exceeded the level of $1000 \mathrm{ng} / \mathrm{L}$ and concentrations of 12 antimicrobials exceeded the level of $100 \mathrm{ng} / \mathrm{L}$. The highest average concentrations of antimicrobials in influent from WWTP2 were recorded for metronidazole $(7400 \mathrm{ng} / \mathrm{L})$, followed by ciprofloxacin $(4300 \mathrm{ng} / \mathrm{L})$, vancomycin (u $3200 \mathrm{ng} / \mathrm{L}$ ), and sulfamethoxazole (3000 ng/L). In other countries, the concentration of metronidazole was lower than $1000 \mathrm{ng} / \mathrm{L}$, that of ciprofloxacin was up to $3800 \mathrm{ng} / \mathrm{L}$ [32] but frequently below $400 \mathrm{ng} / \mathrm{L}$ [33], and that of sulfamethoxazole was up to $7900 \mathrm{ng} / \mathrm{L}$ [34]. There are not much data on vancomycin occurrence in the environment, and it has not been detected in very high concentrations to date as it is primarily used intravenously to treat severe infections in hospitals [35]. The differences in the concentrations of antimicrobials in the influent between two WWTPs can be due to various consumption of antimicrobials in the sampling period and various sources of antimicrobials in these regions. As an example, near WWTP1 is a hospital (449 beds), whereas near WWTP2 is a hospital (458 beds), poultry plant, and galenic laboratory.

\subsection{Antimicrobial Concentrations in Effluent of WWTPS}

The concentrations of 26 antimicrobials in effluents from WWTP1 and WWTP2 are shown in Table 1. In effluents from both WWTPs, the highest average concentrations were observed for azithromycin (up to $650 \mathrm{ng} / \mathrm{L}$ ), sulfamethoxazole (up to $770 \mathrm{ng} / \mathrm{L}$ ), ciprofloxacin (up to $312 \mathrm{ng} / \mathrm{L}$ ), and clindamycin (up to $290 \mathrm{ng} / \mathrm{L}$ ). In effluent from WWTP2, a higher mean concentration of azithromycin but lower of metronidazole was observed. The percentage contribution of the analyzed antimicrobials in influent and effluent of both WWTPs are presented in Figure 1. To summarize, among antimicrobials tested, ciprofloxacin and sulfamethoxazole were the most dominant antimicrobials in influent and effluent from both WWTPs.

Comparing our data from the literature, the results obtained were similar. The concentration of azithromycin was up to $380 \mathrm{ng} / \mathrm{L}$ [36] in Switzerland, that of sulfamethoxazole was up to $1300 \mathrm{ng} / \mathrm{L}$ in Spain [21], and that of clindamycin was up to $5 \mathrm{ng} / \mathrm{L}$ in Australia [32].

\subsection{Antimicrobial Concentrations in Receiving Waters}

In order to assess the impact of antimicrobials on the receiving water bodies, samples were taken upstream and downstream from the WWTPs' discharge (see Section 3.1). The concentrations of 26 antimicrobials in receiving water are shown in Table 1. The river upstream of WWTP1 was more polluted with analyzed antimicrobials than WWTP2 upstream river (Table 1). The highest concentration of sulfamethoxazole (average value: $644 \mathrm{ng} / \mathrm{L}$ ) was detected upstream of WWTP1. While in the upstream of WWTP2, the highest concentration of clarithromycin (average value: $12.2 \mathrm{ng} / \mathrm{L}$ ) was detected. The wastewater discharge from WWTP2 resulted in a significant increase of antimicrobials' concentration in the river. This fact can be explained by the high concentrations of antimicrobials in the case of effluent from WWTP2 (Table 1). In the case of WWTP1, taking into account all antimicrobials, no statistical differences between upstream and downstream were observed. Despite this, the average concentration of azithromycin in WWTP1 downstream was more than 15 times higher compared to the concentration in the upstream. The concentrations of antimicrobials in the receiving waters depend on the concentration of antimicrobials in effluent, distance of sampling, or the different flow rate. In our study, WWTP2 effluent effect on antimicrobials' concentrations in the receiving surface water was observed. 

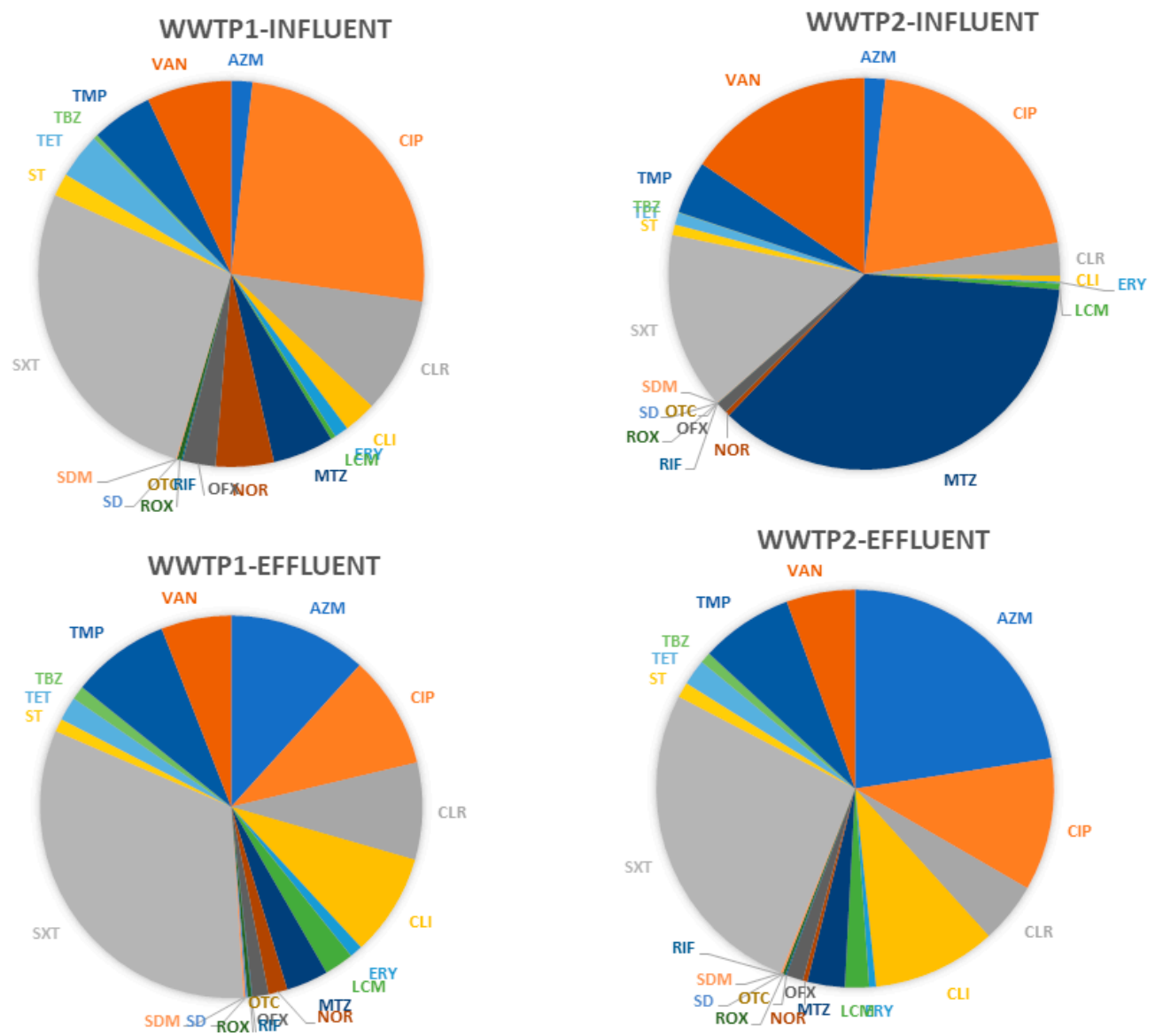

Figure 1. Percentage contribution (\%) of tested antimicrobials in influent and effluent of both WWTPs, $n=3$.

\subsection{Antimicrobials' Removal Efficiency}

The removal efficiency (calculated based on equations described in Section 3.3) of tested antimicrobials was similar for both WWTPs $(p>0.05)$. The average removal efficiency was above $50 \%$ for 12 and 10 out of 20 detected antimicrobials for WWTP1 and WWTP2, respectively (Figure 2). Among the antimicrobials from the sulfonamide group, four were detected in effluents and their removal rate ranged from $17 \%$ to $80 \%$ with an average of $52 \%$. Certain inconsistencies exist in literature about sulfonamide removal, as per the review by Le-Minh et al. [37]. Some researchers have reported an effective removal of sulfonamide [38], although others have mentioned the opposite results [39]. Based on the literature data, this fact might be explained by the differences in operational conditions of each WWTP.

The removal efficiency of trimethoprim was 37\% in WWTP1 and 76\% in WWTP2 ( $p=0.2)$ (the treatment process used in the WWTPs are presented in Section 3.1). Regarding fluoroquinolones, three of them, i.e., norfloxacin, ciprofloxacin, and ofloxacin, were detected in influent of both WWTPs with the average removal being above $80 \%$. The plausible mechanism for the removal of fluoroquinolones from water is sorption to sediment because their concentration was detected as very high in the sludge [40-42] and a slow biodegradation rate was reported [43]. The average removal efficiency for fluoroquinolone antimicrobials estimated by Wang et al. [44] was about 50\%. Rodayan et al. [45] reported values of around $60 \%$, while for WWTPs in Switzerland, higher removal efficiencies were observed, reaching up to $87 \%$ (for norfloxacin) [46]. In the study of Gao et al. [47], the removal efficiencies of WWTPs for fluoroquinolone antimicrobials ranged from $48 \%$ to $72 \%$. 


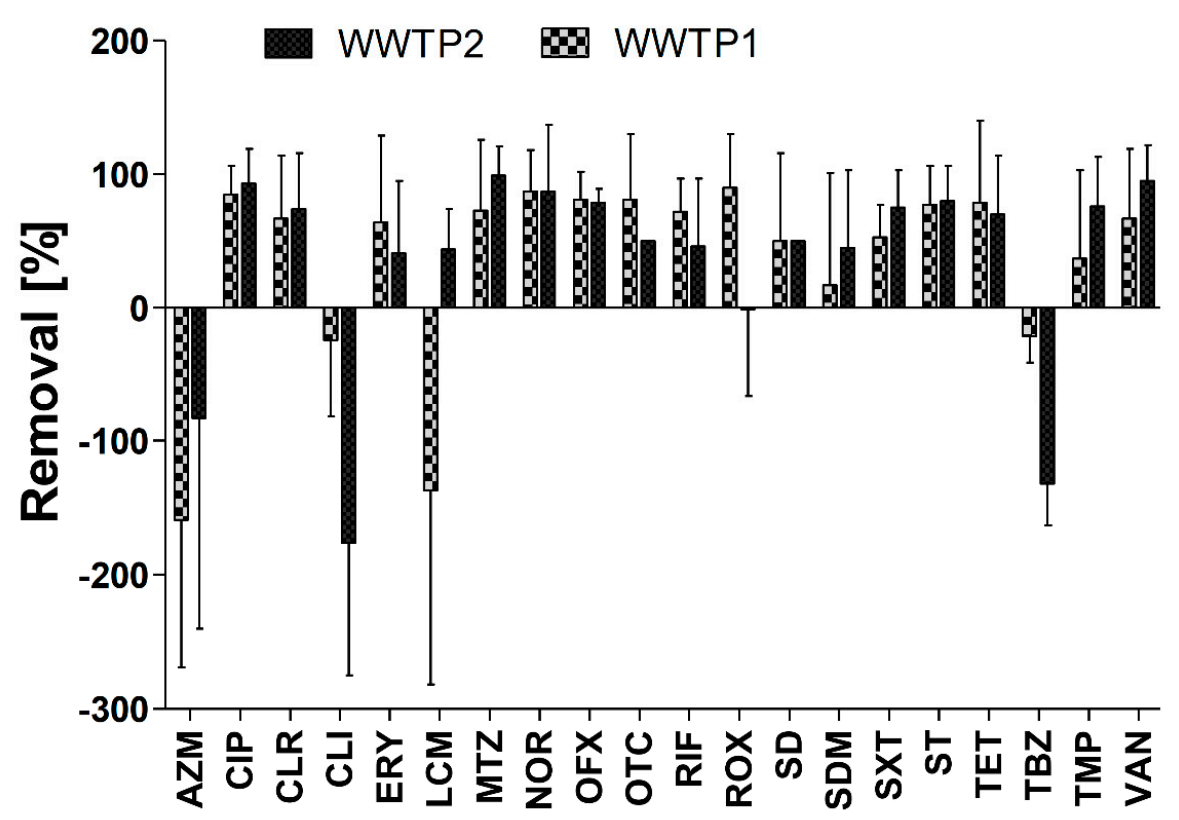

Figure 2. Removal efficiency (\%) of selected antimicrobials in WWTPs calculated based on equations described in Section 3.3.

In this study, a negative removal rate for azithromycin, clindamycin, lincomycin, and thiabendazole was observed (Figure 2). Moreover, for these antimicrobials, a high variance in removal rate was noted, which agrees with previous studies in which certain antimicrobials were reported to be more abundant in effluents than influents $[6,8,10,25,33,48]$.

The negative removal rate has been detected in the literature. For example, Chunhui et al. [49] reported that the removal efficiencies for macrolide antimicrobials in WWTPs was $-4 \%$. Similarly, Gao et al. [47] reported that the removal rate of macrolide antimicrobials was higher, and reached from $-34 \%$ to $69 \%$. The negative removal rate is explained in many ways. First, certain metabolites can return to the parent pharmaceutical during primary and secondary treatment because of glucuronide conjugate hydrolytic cleavage. Second, pharmaceuticals that sorb to organic matter and particles, as well as accumulate in sediments and biofilms, might be resuspended in wastewater during storm water events. Typically, deconjugation or resorption from particles is observed for fluoroquinolones (ciprofloxacin, ofloxacin, and norfloxacin), lincomycin, tetracycline, trimethoprim, and sulfamethoxazole. This issue is particularly relevant to pharmaceuticals that are mainly excreted with bile and feces-like macrolides. During wastewater treatment, they are redissolved, and, therefore, their concentrations in water increase $[10,33]$.

HRT (hydraulic retention time) is one of the major factors influencing the antimicrobial removal efficiency, particularly for compounds that are readily biodegradable and have a low $\mathrm{K}_{\mathrm{d}}$ (low tendency to absorb to sludge) [50]. In this study, HRT was $12 \mathrm{~h}$ in WWTP1 and $24 \mathrm{~h}$ in WWTP2. Other factors influencing the removal efficiency are adsorption coefficients and persistence of the antimicrobials. Lower levels in effluents could be also interpreted as the removal of antimicrobials because of biodegradation and/or chemical and physical transformations, e.g., hydrolysis or sorption to solid matter. Biodegradation/biotransformation and sorption are the two primary mechanisms occurring in the WWTPs. The sorption to sewage sludge is the primary removal mechanism for certain antimicrobials in the samples, e.g., the percentage of the daily load of antimicrobials was $>40 \%$ for azithromycin, ciprofloxacin, ofloxacin, and oxytetracycline in sludge (Table A2), while the lowest value was observed for sulfamethoxazole and lincomycin. The differences between the sorption of antimicrobials depend on their physicochemical properties, such as charge and lipophilicity, the properties of the sludge-like chemical nature, and other factors such as $\mathrm{pH}$ and redox potential [51]. Sorption may occur by hydrophobic interactions with lipophilic cell membranes of the microorganisms or the lipid fractions 
of the suspended solids and electrostatic interactions of positively charged groups of chemicals with negatively charged surfaces of microorganisms or other components of the sludge [33]. Figure 3 shows differences between the concentrations of antimicrobials in wastewater and sludge (separation observed by principal component 1 (PC1) accounted for $45 \%$ of total variance). Two groups were designated by the various amounts of oxytetracycline and norfloxacin in the samples. The relative percentage estimated for the antimicrobial was significantly higher in the sludge than in the wastewater. In wastewater, the relative percentage of metronidazole, lincomycin, and sulfamethoxazole was higher compared to that in the sludge. Similarly, a higher contribution of metronidazole and erythromycin in wastewater and ciprofloxacin in sludge was observed by Ostman et al. [24].
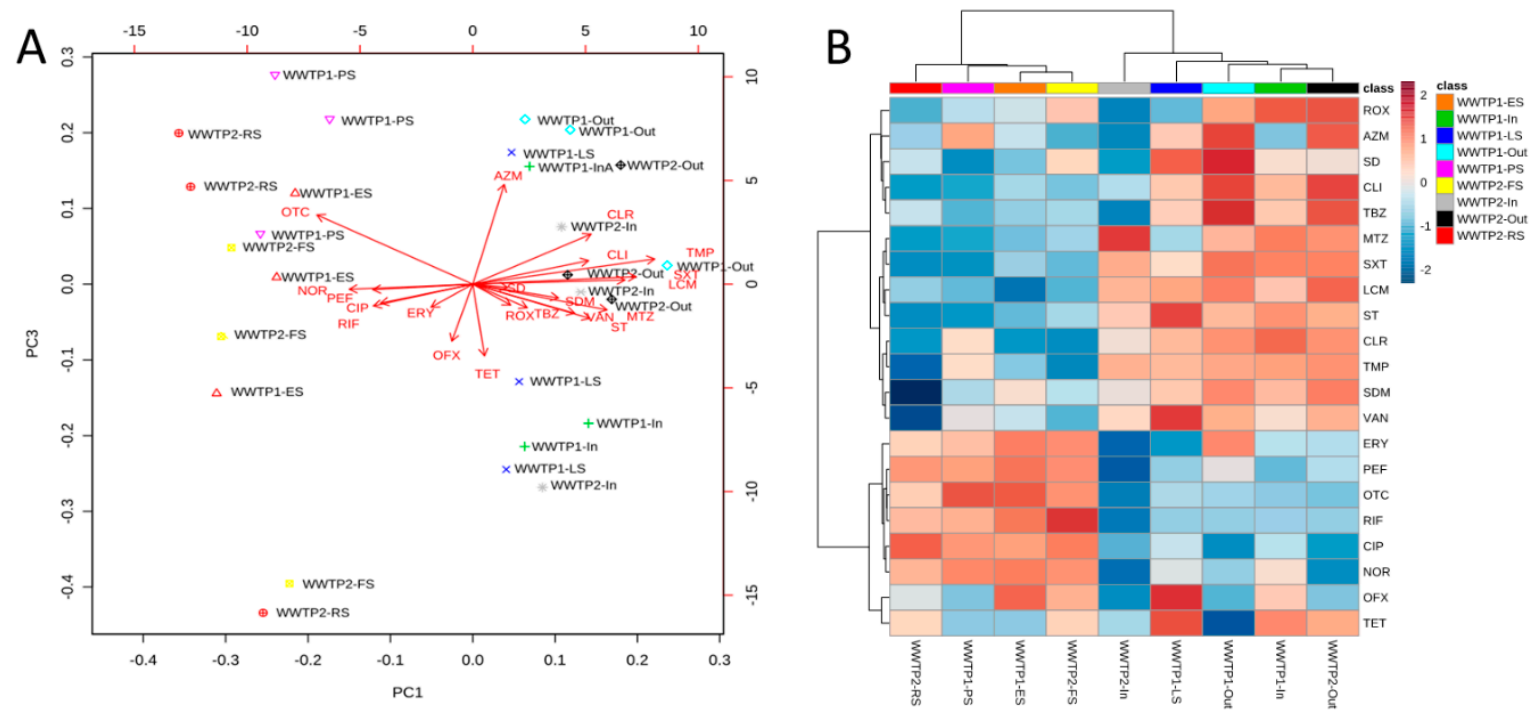

Figure 3. Differences in antimicrobials' concentrations between the wastewater, sludge samples, and leachate collected from WWTP1 and WWTP2. Principal component analysis (PCA) of the all samples (A). Variables of a data matrix are represented as arrows. Visualization of the observed relations on the heat map (B). ES, excessive sludge; FS, fermented sludge; In, influent; LS, leachate; Out, effluent; PS, primary sludge; RS, residual sludge.

Our results showed that leachate from WWTP1 contained a significant amount of antimicrobials. The mean concentrations of nine antimicrobials were above $100 \mathrm{ng} / \mathrm{L}$ (Table 1). The concentrations of azithromycin, ciprofloxacin, norfloxacin, ofloxacin, sulfamethoxazole, and vancomycin were comparable to those in the WWTP1 influent. The results obtained suggest that the antimicrobials are strongly sorbed to solids (Table A1). The antimicrobials bound to solids can be leached to the environment, which should be taken into consideration when conducting the risk assessment. In the Table $A 1$, the $K_{d}$ values for tested antimicrobials are presented. Generally, $K_{d}$ is used to estimate the mobility and distribution of the pharmaceuticals in the environment [41,52]. Compounds with low $\mathrm{K}_{\mathrm{d}}$ are potentially mobile from soil to the water (through leaching or runoff). According to our study, the most mobile antimicrobials are trimethoprim $\left(\log \mathrm{K}_{\mathrm{d}}=5.8\right)$, sulfamethoxazole $\left(\log \mathrm{K}_{\mathrm{d}}=5.1\right)$, lincomycin $\left(\log K_{d}=5.2\right)$, clarithromycin $\left(\log K_{d}=5.7\right)$, clindamycin $\left(\log K_{d}=5.7\right)$, and thiabendazole $\left(\log K_{d}=5.9\right)$.

\subsection{Antimicrobials' Concentrations in Sewage Sludge from WWTPs}

Fifteen antimicrobials in the primary (WWTP1-PS) and excessive sludge (WWTP1-ES) from WWTP1 as well as in the fermented (WWTP2-FS) and residue sludge (WWTP2-RS) from WWTP2 were detected (Table 2). Results obtained indicated that a part of the antimicrobials were adsorbed to the sludge along the whole technological process. 
Table 2. Mean and standard deviation $(n=3)$ of target antimicrobial concentration (ng/g dry weight) in sewage sludge samples in two wastewater treatment plants (WWTPs) located in Poland at Silesian (WWTP1) and Warmian-Masurian Voivodship (WWTP2).

\begin{tabular}{|c|c|c|c|c|c|c|c|c|c|c|c|c|}
\hline & \multicolumn{2}{|c|}{ WWTP1-PS } & \multicolumn{2}{|c|}{ WWTP1-ES } & \multicolumn{2}{|c|}{ WWTP2-RS } & \multicolumn{2}{|c|}{ WWTP2-FS } & \multicolumn{2}{|c|}{ WWTP1-RS ${ }^{1}$} & \multirow{2}{*}{ MDL } & \multirow{2}{*}{ MQL } \\
\hline & Mean & SD & Mean & SD & Mean & SD & Mean & SD & Mean & SD & & \\
\hline $\mathrm{AZM}$ & 1260 & 690 & 370 & 280 & 82 & 75 & 1040 & 940 & 100 & 110 & 23 & 79 \\
\hline CIP & 12500 & 6900 & 6200 & 2000 & 6100 & 5500 & 28000 & 22000 & 7800 & 4400 & 490 & 1670 \\
\hline CLR & 289 & 52 & 18 & 14 & 18 & 23 & 150 & 180 & 3.0 & 0.8 & 2.2 & 7.4 \\
\hline CLI & 40 & 25 & 58 & 35 & 29 & 29 & 47 & 30 & 9.1 & 5.6 & 1.3 & 4.5 \\
\hline LCM & 4.3 & 3.2 & 1.5 & 2.0 & 2.5 & 2.6 & 19 & 24 & 0.13 & 0.05 & 0.2 & 0.6 \\
\hline NOR & 5300 & 3200 & 3600 & 2500 & 1600 & 1400 & 3400 & 2300 & \multicolumn{2}{|c|}{$<\mathrm{MDL}$} & 370 & 1270 \\
\hline OFX & 810 & 890 & 640 & 510 & 300 & 190 & 480 & 120 & 36 & 21 & 12 & 41 \\
\hline OTC & 590 & 410 & 320 & 230 & 50 & 35 & 190 & 200 & 4.0 & 6.5 & 0.2 & 0.7 \\
\hline PEF & 250 & 150 & 190 & 110 & 140 & 120 & 256 & 81 & \multicolumn{2}{|c|}{$<\mathrm{MDL}$} & 29 & 100 \\
\hline ROX & 11.4 & 7.8 & \multicolumn{2}{|c|}{$<\mathrm{MDL}$} & \multicolumn{2}{|c|}{$<\mathrm{MDL}$} & \multicolumn{2}{|c|}{$<\mathrm{MDL}$} & 0.22 & 0.26 & 12 & 40 \\
\hline SD & \multicolumn{2}{|c|}{$<\mathrm{MDL}$} & \multicolumn{2}{|c|}{$<\mathrm{MDL}$} & 1.1 & 0.8 & 7.7 & 11 & 0.14 & 0.18 & 1.1 & 3.7 \\
\hline SDM & 12 & 14 & 13 & 14 & 7.5 & 11 & & & 0.29 & - & 0.6 & 2.0 \\
\hline SXT & \multicolumn{2}{|c|}{$<\mathrm{MDL}$} & 81 & 54 & \multicolumn{2}{|c|}{$<\mathrm{MDL}$} & \multicolumn{2}{|c|}{$<\mathrm{MDL}$} & 5.9 & 9.4 & 41 & 140 \\
\hline TET & 82 & 50 & 40 & 13 & 58 & 29 & 201 & 95 & 25 & 29 & 0.7 & 2.5 \\
\hline TBZ & 19.5 & 5.2 & 15.6 & 5.8 & 43 & 43 & 49 & 22 & 8.3 & 6.2 & 0.6 & 2.2 \\
\hline TMP & 170 & 110 & 5.7 & 4.4 & \multicolumn{2}{|c|}{$<\mathrm{MDL}$} & \multicolumn{2}{|c|}{$<\mathrm{MDL}$} & 2.6 & 1.7 & 0.5 & 1.5 \\
\hline VAN & 363 & 55 & 181 & 91 & 36 & 30 & \multicolumn{2}{|c|}{$<\mathrm{MDL}$} & 370 & 130 & 32 & 110 \\
\hline
\end{tabular}

CFR (350 ng/g), FLRX (12 ng/g), LOM (7.9 ng/g), NAL (3.3 ng/g), MTZ (25 ng/g), RIF (150 ng/g), ST (30 ng/g), SDD (39 ng/g) were not detected. Their MDLs (method detection limits) are provided in parentheses; MQL, method quantitation limit; WWTP-PS, primary sludge; WWTP-ES, excessive sludge; WWTP-FS, fermented sludge, WWTP-RS residual sludge; ${ }^{1}$ calculated based to the lowest $K_{d}$ observed and concentration of antimicrobials in leachate.

In our study the highest concentrations for fluoroquinolones, such as ciprofloxacin (up to $57 \mu \mathrm{g} / \mathrm{g}$ ), norfloxacin (up to $9.5 \mu \mathrm{g} / \mathrm{g}$ ), ofloxacin (up to $2.0 \mu \mathrm{g} / \mathrm{g}$ ), and azithromycin (up to $2.3 \mu \mathrm{g} / \mathrm{g}$ ), were determined in the sludge samples (data not presented). In China, the concentration of norfloxacin, ofloxacin, and ciprofloxacin in sludge was determined from all the major provincial cities, ranging ranged from 0.1 to $15.7 \mu \mathrm{g} / \mathrm{g}$, from 0.3 to $7.9 \mu \mathrm{g} / \mathrm{g}$, and from 0.1 to $4.7 \mu \mathrm{g} / \mathrm{g}$, respectively [53]. In Switzerland (up to $3.3 \mu \mathrm{g} / \mathrm{g}$ ) and Sweden (up to $4.2 \mu \mathrm{g} / \mathrm{g}$ ), the maximum concentration of norfloxacin was lower than that in China and presented in Poland. Furthermore, the maximum level of other fluoroquinolones was higher in Poland than in Switzerland (up to $0.9 \mu \mathrm{g} / \mathrm{g}$ for ciprofloxacin) and Sweden (up to $4.8 \mu \mathrm{g} / \mathrm{g}$ for ciprofloxacin and up to $2.0 \mu \mathrm{g} / \mathrm{g}$ for ofloxacin) [54,55]. The concentration of azithromycin in the activated sludge was up to $0.16 \mu \mathrm{g} / \mathrm{g}$ and $0.056 \mu \mathrm{g} / \mathrm{g}$ in Germany and Switzerland, respectively, and the values were lower compared to those for Poland (up to $0.71 \mu \mathrm{g} / \mathrm{g}$ ) [56]. Recently, a study from Germany reported the concentration of azithromycin and ciprofloxacin in sediments to be up to $0.33 \mu \mathrm{g} / \mathrm{g}$ and $0.71 \mu \mathrm{g} / \mathrm{g}$ [41], respectively.

\subsection{Antimicrobial Resistance Risk Assessment}

The risk factor of antimicrobial resistance selection (named as antimicrobial resistance risk, defined as preferential outgrowth of antimicrobial-resistant bacteria) in wastewater was high for the following antimicrobials: azithromycin, ciprofloxacin, clarithromycin, metronidazole, and trimethoprim (Figure 4A). As expected, this factor was the highest in influent from both WWTPs. 
Similar results were obtained by Ostman et al. [24], who observed a high risk of resistance selection in influents in Swedish WWTPs because of the prevalence of ciprofloxacin and metronidazole. No risk for azithromycin was detected in their study.
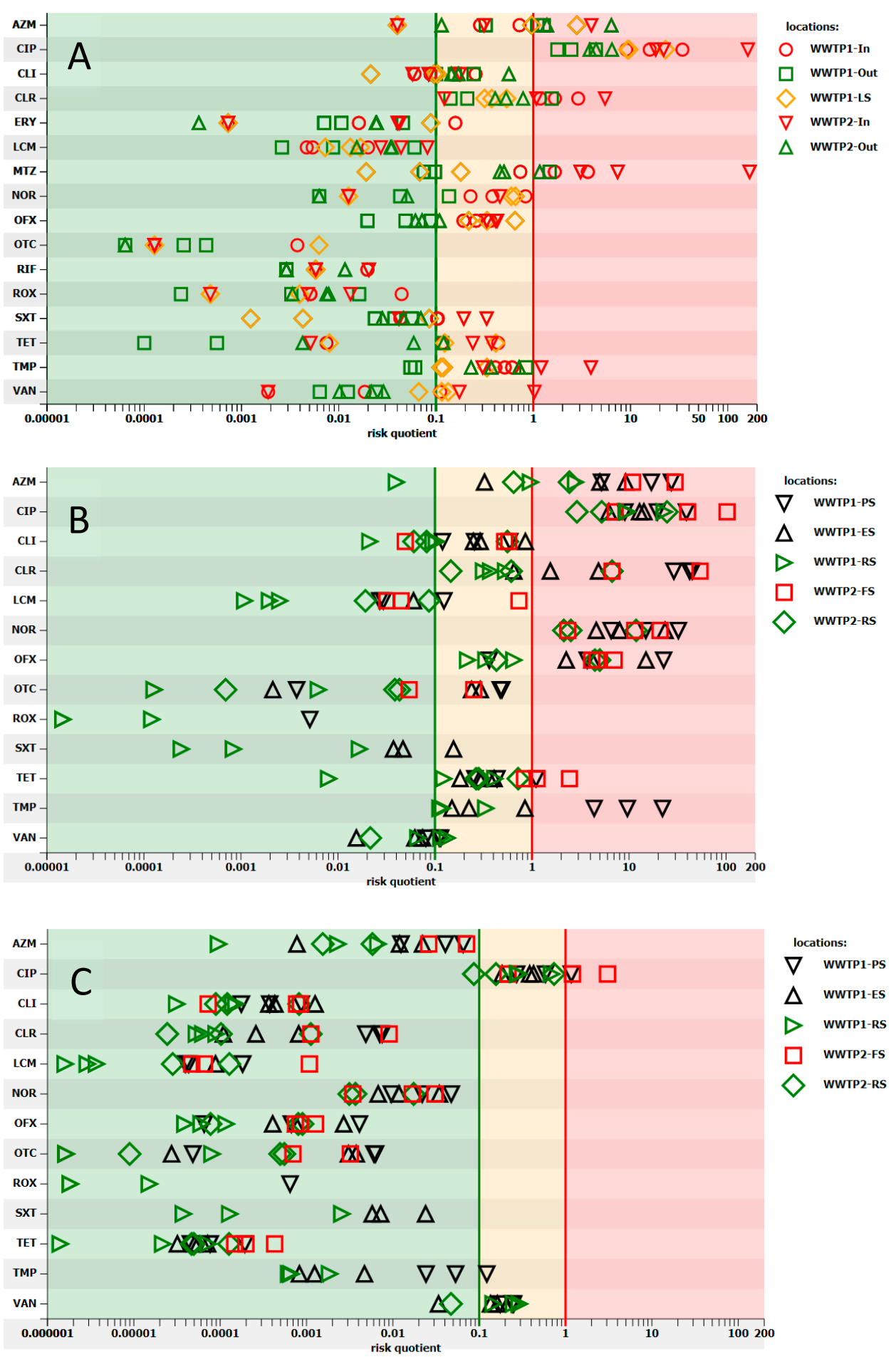

Figure 4. Estimation of risk quotients of resistance selection for the antimicrobials occurring in wastewater (A), sludge (B), and sludge-amended soil (C). Risk quotient below 0.1 indicates minimal risk (green area), between 0.1 and 1 is medium risk (orange area), and over 1 is high risk (red area). ES, excessive sludge; FS, fermented sludge; In, influent; LS, leachate; Out, effluent; PS, primary sludge; RS, residual sludge. 
It is interesting, the notable antimicrobial resistance risk was also predicted upstream of both WWTPs. High antimicrobial resistance risk for ciprofloxacin and medium risk for azithromycin, clarithromycin, and clindamycin was observed in the case of WWTP1, while medium antimicrobial resistance risk for ciprofloxacin was noted in the case of WWTP2. Downstream WWTP1, on top of the previous risk, the risk for metronidazole turned medium, whereas the risk for azithromycin rose to high. In the case of WWTP2, the risk for ciprofloxacin rose from medium to high and the medium risk for ofloxacin, clarithromycin, and clindamycin appeared (data not presented).

The antimicrobial resistance risk was high for azithromycin, ciprofloxacin, clarithromycin, norfloxacin, trimethoprim, ofloxacin, and tetracycline in sludge (Figure 4B). Interestingly, residual sludge could pose a risk to the environment, particularly because of the presence of fluoroquinolones and macrolides. Mean $\mathrm{PEC}_{\text {soil }}$ (predicted environmental concentration in soil) was mainly lower than $1 \mathrm{ng} / \mathrm{g}$ and higher concentrations were observed for ciprofloxacin (up to $41 \mathrm{ng} / \mathrm{g}$ ), norfloxacin (up to $7.8 \mathrm{ng} / \mathrm{g}$ ), ofloxacin (up to $1.2 \mathrm{ng} / \mathrm{g}$ ), and azithromycin (up to $2.3 \mathrm{ng} / \mathrm{g}$ ) (Table A3). When RQ was analyzed, a high risk for soil was noted for ciprofloxacin (Figure 4C). The data on risk assessment on the antimicrobial resistance selection in sludge and sludge-amended soil presented in this paper are the first.

\subsection{Environmental Risk Assessment}

The high risk was observed for both cyanobacteria (Figure 5A) and eukaryotic species (Figure 5B) due to azithromycin, clarithromycin and sulfamethoxazole in effluents. Furthermore, medium risk was predicted for chronic exposure of cyanobacteria to ciprofloxacin, erythromycin, norfloxacin, and ofloxacin (in effluents). The same level of risk was evaluated for chronic exposure of eukaryotic organisms to ciprofloxacin, erythromycin, and roxithromycin (in effluents). Verlicchi et al. [33] published a review, which reported that six antimicrobials posed a high environmental risk for eukaryotes, i.e., erythromycin, ofloxacin, sulfamethoxazole, clarithromycin, tetracycline, and azithromycin. Harrabi et al. [6] observed a high risk for ofloxacin, ciprofloxacin, azithromycin, sulfamethoxazole, and trimethoprim for eukaryotic species; however, clarithromycin was not evaluated. In their studies, the predicted no effect concentration (PNEC) was, however, calculated differently compared to our study. The authors obtained PNEC values 1000 times lower than the toxicity values found for the most sensitive eukaryotic species that were assayed [6,33]. In our study, other factors, i.e.1000, 100, 50 or10, were used to calculate PNEC. Thus, RQ values obtained for the same concentrations of antimicrobials were lower.

In the case of upstream of WWTP1, there was high risk for cyanobacteria posed by azithromycin, norfloxacin, and sulfamethoxazole, whereas medium risk was observed for ciprofloxacin and clarithromycin. The risk for eukaryote was also observed but the level of the risk was different for the antimicrobials, e.g., for clarithromycin high risk was estimated, and for azithromycin, ciprofloxacin, and sulfamethoxazole medium risk was noted.

None of the antimicrobials posed high risk from upstream of WWTP2. However, medium risk was posed by azithromycin, clarithromycin for cyanobacteria, and medium risk for eukaryote posed by clarithromycin were observed. The medium risk for cyanobacteria posed by ciprofloxacin, ofloxacin, clarithromycin, and sulfamethoxazole in WWTP2 downstream was noted. The risk of toxicity due to azithromycin content increased from medium to high comparing the upstream and downstream. Two more antimicrobials, i.e., azithromycin and ciprofloxacin, were predicted to cause the medium risk for eukaryote.

The RQ calculated for cyanobacteria exposed to sludge was medium for azithromycin (primary sludge up to 0.36 , excessive sludge up to 0.12 , fermented sludge up to 0.39 ) and clarithromycin (primary sludge up to 0.13 , fermented sludge up to 0.16 ). No data on risk assessment on antimicrobial presence in sludge was found in literature to compare with our data.

Antimicrobials are designed to act on prokaryotic organisms; thus, environmental bacteria are more likely to be adversely affected compared to other environmental species such as aquatic invertebrates 
and vertebrates. However, compared to cyanobacteria, certain microalgae and macrophytes are more sensitive to certain antifolate and quinolone antimicrobials [27].
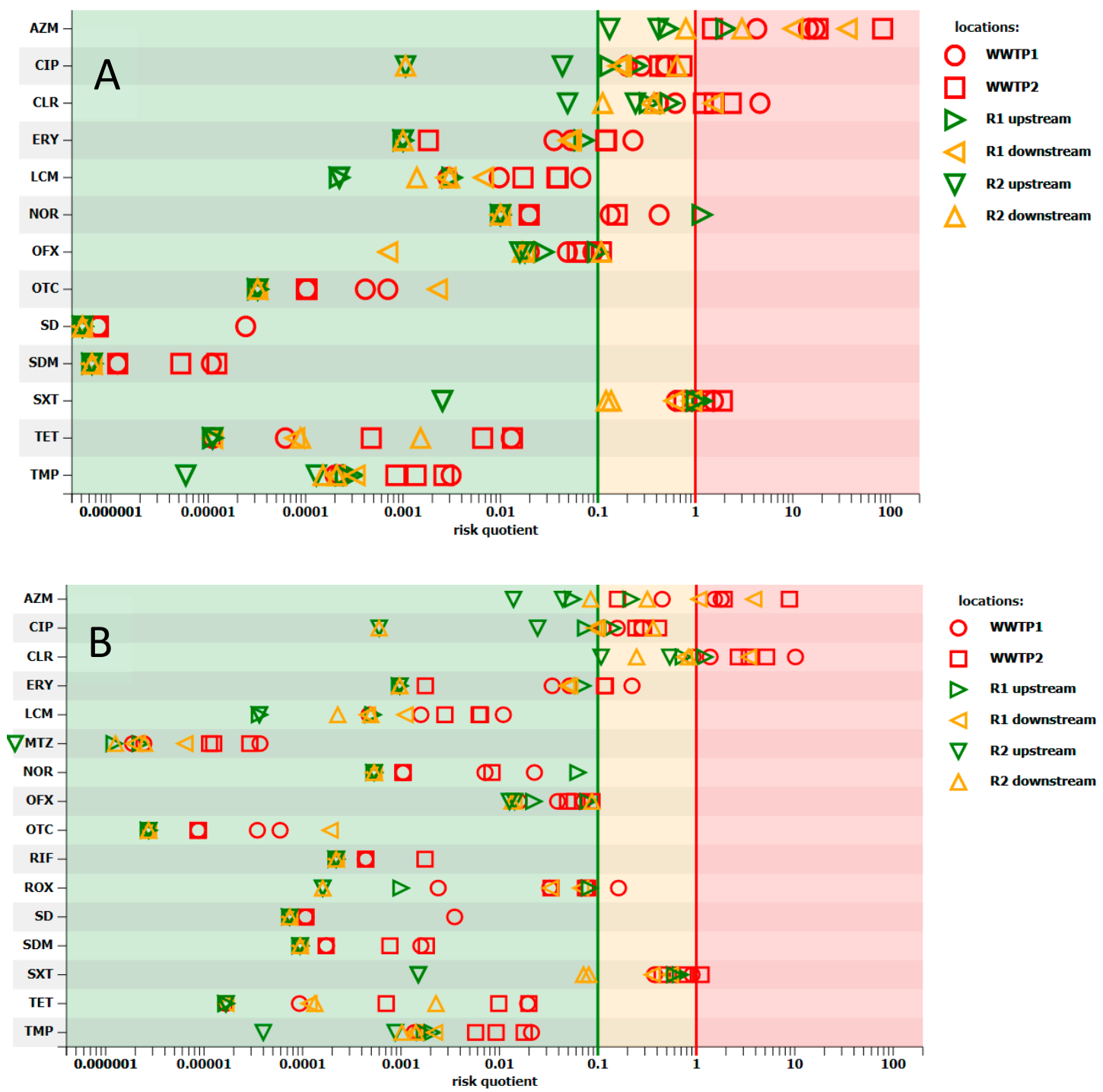

Figure 5. Estimation of risk quotients of chronic exposure of cyanobacteria (A) and eukaryotic organisms (B) to the antimicrobials occurring in effluents and receiving water. Calculations were based on the measured concentration of antimicrobials in wastewater and PNEC calculated based on [27]. Risk quotient below 0.1 indicates minimal risk (green area), between 0.1 and 1 is medium risk (orange area), and over 1 is high risk (red area).

\section{Materials and Methods}

\subsection{Description of WWTPs and Sample Collection}

The raw influent, final effluent, leachate, and sludge samples (i.e., primary sludge and excessive sludge (WWTP1) or fermented sludge and residual sludge (WWTP2)) were collected from two Polish WWTPs during the three sampling campaigns: (1) In June/July 2018, (2) in October 2018, and (3) in December 2018. Simultaneously, the receiving river water samples from upstream and downstream (WWTP1, $0.25 \mathrm{~km}$; WWTP2, $1.8 \mathrm{~km}$ ) of the outlet were collected. Each sample was collected in triplicate. The rivers' average annual flow is $3.5 \mathrm{~m}^{3} / \mathrm{s}$ (WWTP1) and $3.7 \mathrm{~m}^{3} / \mathrm{s}$ (WWTP2).

WWTP1 is located in one of the cities from Metropolitan Association of Upper Silesia, one of the largest urban areas in the EU and the center of Poland's industries, particularly coal and metal, 
with a density of 1600 people per $\mathrm{km}^{2}$ [57], geographical coordinates: $\mathrm{N} 50^{\circ} 5^{\prime} 35.881$, E $19^{\circ} 3^{\prime} 32.202$. WWTP2 is located in the forested and agriculture area of Warmian-Masurian Voivodship in the city with a density of 1960 people per $\mathrm{km}^{2}$ [57], geographical coordinates: $\mathrm{N} 53^{\circ} 48^{\prime} 46.700$, E $20^{\circ} 26^{\prime} 55.800$.

In 2018, WWTP1 had an equivalent population of 189,332 inhabitants, the average flow rate was $26,830 \mathrm{~m}^{3} / \mathrm{d}$, and the plant was operated with a hydraulic retention time (HRT) of $\sim 12 \mathrm{~h}$ and a solid retention time (SRT) of 25 days, while WWTP2 served a population equivalent of 250,000 inhabitants, and had a flow rate of $32,130 \mathrm{~m}^{3} / \mathrm{d}$, HRT of $24 \mathrm{~h}$, and SRT of 87 days. Both WWTPs receive domestic, hospital, and industrial wastewaters and treat wastewater with a mechanical-biological system with elevated removal of nutrients. The biological section of WWTP1 included sequential reactors activated sludge chambers (the system of chambers of different oxygen conditions: anaerobic, anoxic, and aerobic), secondary settling tank, and anoxic chamber. In the case of WWTP2, the biological part included a pre-denitrification chamber, phosphorus removal tank, nitrification/denitrification chambers, and secondary settling tanks. Sewage sludge produced in the WWTP1 was subjected to a thickening process, methane fermentation, and dehydration. The leachate produced during sludge fermentation (WWTP1-FS) was returned to the pumping station and again treated. The sewage sludge from WWTP2 was used as a soil improver. The detailed description and technical parameters of both WWTPs are presented by Buta et al. [58].

All samples were collected in triplicate and placed in the sterile glass bottles in volumes of 1-2 liters. Sludge samples were collected after mechanical concentration (primary sludge, WWTP1-PS), after gravity concentration (excessive sludge, WWTP1-ES), after an open fermentation pool (fermented sludge, WWTP2-FS), and after all processes (residue sludge, WWTP2-RS), i.e., sludge for management. Then the samples were transported to the laboratory on the same day and stored at a temperature of $4{ }^{\circ} \mathrm{C}$ until analysis.

\subsection{Analysis of Antimicrobials' Concentrations}

\subsubsection{Chemicals}

This study targeted 26 antimicrobials including: Azithromycin (AZM), cefadroxil (CFR), ciprofloxacin (CIP), clarithromycin (CLR), clindamycin (CLI), erythromycin (ERY), fleroxacin (FLRX), lincomycin (LCM), lomefloxacin (LOM), metronidazole (MTZ), nalidixic acid (NAL), norfloxacin (NOR), ofloxacin (OFX), oxytetracycline (OTC), pefloxacin (PEF), rifampicin (RIF), roxithromycin (ROX), sulfadiazine (SD), sulfadimethoxine (SDM), sulfamethazine (SDD), sulfamethoxazole (SXT), sulfathiazole (ST), tetracycline (TET), thiabendazole (TBZ), trimethoprim (TMP), and vancomycin (VAN). All pharmaceutical standards for target antimicrobials were of high purity grade $(>90 \%)$. All compounds were purchased from Sigma-Aldrich (Darmstadt, Germany). Only trimethoprim was sourced from The National Drug Research Institute in Warsaw, Poland. Isotopically labeled compounds used as mixture of internal standards $(1 \mu \mathrm{g} / \mathrm{mL}$ in methanol), i.e., azithromycin-C13, ciprofloxacin-D8, sulfamethoxazole-D4, clindamycin-D4, erythromycin-C13D3, ofloxacin-D8, tetracycline-D6, and trimethoprim-D9 (Toronto Research Chemicals, Toronto, Canada), were added to each sample before extraction $(500 \mu \mathrm{L})$. Solvents, such as HPLC-grade methanol, acetonitrile (LiChrosolv), and formic acid $(98 \%)$, were obtained from Merck (Darmstadt, Germany). Moreover, ultrapure water was obtained from a Millipore water purification system (Milli-Q water). All working solutions were prepared prior to analysis.

\subsubsection{Preparation of Water and Sewage Sludge Samples}

Aqueous samples were filtered through glass fiber filters (GF/C, Whatman, Pittsburgh, PA, USA) and membrane filters ( $0.2 \mu \mathrm{m}$, Sartorius Goettingen, Germany). To $200 \mathrm{~mL}$ volumes of filtrate, $200 \mathrm{mg}$ of ethylenediaminetetraacetic acid was added. Then, solid-phase extraction (SPE) (Oasis HLB cartridges, $3 \mathrm{~mL}, 400 \mathrm{mg}$, Waters Corp., Milford, MA, USA) using a Phenomenex vacuum system (Torrance, CA, USA) was performed. The elutions were made with pure methanol $(3 \times 2 \mathrm{~mL})$. The eluents were 
evaporated to dryness under a stream of nitrogen (99.999\% purity, Multax, Poland) at $40{ }^{\circ} \mathrm{C}$ and reconstituted in a methanol-water mixture $(10: 90, v / v)(1 \mathrm{~mL})$.

Sludge samples were centrifuged at $5000 \mathrm{rpm}$ for $5 \mathrm{~min}$ and the supernatant was discarded. Five $\mathrm{g}$ of WWTP2-RS or $10 \mathrm{~g}$ of the other samples were placed into $50 \mathrm{~mL}$ polypropylene tubes, which were then mixed with $9 \mathrm{~mL}$ of $30 \mathrm{mMpotassium}$ phosphate monobasic solution and $1 \mathrm{~mL}$ of methanol, and extracted for $20 \mathrm{~min}$ using $10 \mathrm{~mL}$ of acetonitrile with $1 \%$ formic acid and modified QUECHERS salts ( $4 \mathrm{~g} \mathrm{MgSO}_{4}, 1 \mathrm{~g} \mathrm{NaCl}, 1 \mathrm{~g} \mathrm{Na}_{3}$ Citrate, and $0.5 \mathrm{~g} \mathrm{Na}_{2} \mathrm{Citrate}_{\mathrm{H}_{2} \mathrm{O}}$ ). Next, the samples were centrifuged for $5 \mathrm{~min}$ at $5000 \mathrm{~g}$. The samples were then cleaned by incubating $9 \mathrm{~mL}$ of extract with $500 \mathrm{mg}$ octadecyl sorbent and $750 \mathrm{mg}$ of $\mathrm{MgSO}_{4}$. They were then vortexed for $5 \mathrm{~min}$ at $1200 \mathrm{rpm}$ and centrifuged for $5 \mathrm{~min}$ at $5000 \mathrm{rpm}$. Eight $\mathrm{mL}$ of the extract (organic layer) under a nitrogen stream at $40{ }^{\circ} \mathrm{C}$ and reconstituted in $0.5 \mathrm{~mL}$ of a mixture of methanol-water (10:90) was evaporated. The isotopically labeled compounds were used as an internal standards mixture to each sample before extraction $(50 \mu \mathrm{L})$.

\subsubsection{Antimicrobial Detection by LC-MS/MS Analysis}

Antimicrobial concentrations were analyzed by high-performance liquid chromatography coupled to mass spectrometry with a Hybrid Triple Quadrupole/Linear Ion trap mass spectrometer (QTRAP®4000, AB SCIEX, Framingham, MA, USA). LC analysis was performed using an Agilent 1260 Infinity (Agilent Technologies, Santa Clara, CA, USA) equipped with a degasser, thermostated autosampler, and binary pump, and connected in series to an AB Sciex 4000 QTRAP mass spectrometer equipped with a Turbo Ion Spray source that was operated in both positive mode and negative mode. The curtain gas, ion source gas 1 , ion source gas 2, and collision gas (all high purity nitrogen) were set at $35 \mathrm{psi}, 60 \mathrm{psi}, 40 \mathrm{psi}$, and "medium" instrument units, respectively, and the ion spray voltage and source temperature were set at $5000 \mathrm{~V}$ and $600^{\circ} \mathrm{C}$, respectively. Chromatographic separation was achieved with a Kinetex RP-18 column $(100 \mathrm{~mm} \times 4.6 \mathrm{~mm}, 2.6 \mu \mathrm{m})$ supplied by Phenomenex (Torrance, CA, USA). The column was maintained at $40{ }^{\circ} \mathrm{C}$ and the flow rate was $0.5 \mathrm{~mL} / \mathrm{min}$. The mobile phase consisted of HPLC-grade water with $0.2 \%$ formic acid as eluent $A$ and acetonitrile with $0.2 \%$ formic acid as eluent B. The gradient (\%B) was as follows: $0 \mathrm{~min}$. $10 \%, 1 \mathrm{~min}$. $10 \%, 25 \mathrm{~min}$. $90 \%$, and $35 \mathrm{~min}$. $90 \%$. The injection volume was $10 \mu \mathrm{L}$. The target compounds were analyzed in multiple reaction monitoring (MRM) mode in positive ionization mode (ESI + ), monitoring two transitions between the precursor ion and the most abundant fragment ions for each compound. Internal standards were attributed to analyzed compounds based on similarities between chemical structures of surrogate and analyzed compound (according to the Tanimoto similarity index). The LC-MS method was validated using three quality control levels (low, medium, and high) prepared on effluents. The interday precision higher than $15 \%$ was observed for cefadroxil (up to $22 \%$ ), norfloxacin (up to $22 \%$ ), lomefloxacin (up to $24 \%$ ), and azithromycin (up to $35 \%$ ) in case of wastewater and for cefadroxil (up to 23\%), azithromycin (up to $26 \%$ ), roxithromycin (up to $34 \%$ ), and clarithromycin (up to $38 \%$ ) in case of sediments. Significant matrix effect (lower than $85 \%$ or higher than $115 \%$ ) was observed for 12 compounds in the case of wastewater and 21 in the case of sediments. Additionally to internal standard addition to control the matrix effect, each sample was tested without and after fortification with antimicrobials.

The following blanks were used: the HPLC blank (10\% methanol) and the method blank (Milli-Q water, calcinated sand) to evaluate the contamination resulting from the complete preparation and analytical procedure. The positive control (water or sand fortified with pharmaceuticals) was also applied. Then, the obtained results were adjusted with recovery and matrix effect. The method detection limit (MDL) and method quantitation limit (MQL) for the entire method (including extraction) were determined as the amount of analyte in matrix spiked with signal-to-noise ratios $(\mathrm{S} / \mathrm{N})$ of 3:1 and 10:1, respectively. For the pharmaceuticals already present in samples, MDL and MQL were estimated by determining the $\mathrm{S} / \mathrm{N}$ of the minimum measured concentrations and extrapolating to $\mathrm{S} / \mathrm{N}$ values of 3 and 10 , respectively. 


\subsection{Calculations}

The following parameters were calculated:

Antimicrobial removal (RE) calculated using Equations (1) and (2) according to Douziech et al. [59]:

$$
\begin{aligned}
\operatorname{RE}[\%] & =(1-\exp (\mathrm{RR})) \times 100 \% \\
\mathrm{RR} & =\ln \left(\mathrm{C}_{\mathrm{EWW}} / \mathrm{C}_{\mathrm{IWW}}\right)
\end{aligned}
$$

where RE is the removal of antimicrobials during treatment [\%], RR (response ratio (effect size)) is measured per WWTP and antimicrobial, $\mathrm{C}_{\mathrm{EWW}}$ is the mean of the effluent wastewater concentration of the antimicrobial $(n=3)$, and $C_{\text {IWW }}$ is the mean of the influent wastewater concentration of the antimicrobial $(n=3)$.

PNEC (predicted no effect concentration) for resistance selection in wastewater was calculated according to Bengtsson-Palme and Larsson [28], whereas PNEC for eukaryotic species was calculated as described by Page et al. [27]. Depending on the number of long-term toxicity tests performed, i.e., no test, the test on one, two, or three trophic levels, the lowest obtained NOEC (no observable effect level) or $\mathrm{EC}_{50}$ (half maximal effective concentration) was divided by 1000, 100, 50, or 10 [60]. PNEC for cyanobacteria was obtained by dividing the NOEC or $\mathrm{EC}_{50}$ by 10 . All PNEC values were presented in Table A4.

PNEC for soil $\left(\mathrm{PNEC}_{\text {soil }}\right)$ and sludge $\left(\mathrm{PNEC}_{\text {sludge }}\right.$ ) was obtained by multiplying PNEC with $\mathrm{K}_{\mathrm{d}}$ (solid/liquid partition coefficient, Table A2). $\mathrm{K}_{\mathrm{d}}$ was calculated as the ratio of the concentration of an antimicrobial on a solid phase (sludge) divided by the equilibrium concentration in the contacting liquid phase (wastewater). PNEC values for resistance selection can be found in Table A5.

Risk quotients (RQs) were calculated using Equation (3):

$$
\begin{gathered}
\mathrm{RQ}_{\text {wastewater }}=\mathrm{MEC}_{\text {wastewater }} / \mathrm{PNEC} \\
\mathrm{RQ}_{\text {sludge }}=\mathrm{MEC}_{\text {sludge }} / \mathrm{PNEC}_{\text {sludge }} \\
\mathrm{RQ}_{\text {wastewater }}=\mathrm{PEC}_{\text {soil }} / \mathrm{PNEC}_{\text {soil }}
\end{gathered}
$$

where $\mathrm{PEC}_{\text {soil }}$ is predicted environmental concentration in soil (Table A3), MEC is measured environmental concentration, and PNEC is predicted no effect concentration.

The risk ranking criterion was $R Q<0.1$, minimal risk; $1>R Q \geq 0.1$, medium risk; and $R Q>1$, high risk [61].

Predicted daily load of the antimicrobial into WWTP (PLoad) from actual consumption data of the product using Equation (6) is:

$$
\text { PLoad }=\text { TOTAL } \cdot W W T P /(I N H A B \cdot 30)
$$

where PLoad is the predicted daily load of the antimicrobial into WWTP $(\mathrm{mg} / \mathrm{d})$, TOTAL is the total monthly consumption of the pharmaceutical in a country $(\mathrm{mg})$, WWTP is an equivalent number of inhabitants in a WWTP, and INHAB is the number of inhabitants in a country $(38,000,000)$.

Average daily load of the antimicrobial into a WWTP from the measured data using Equation (7) is:

$$
\operatorname{Load}_{W+S}=\operatorname{Load}_{W}+\operatorname{Load}_{S}=C_{W} \cdot \text { Flow }+C_{S} \cdot \text { PS }
$$

where Load $_{W+S}$ is the average total daily load of antimicrobial into WWTP $(\mathrm{mg} / \mathrm{d})$, Load $\mathrm{W}_{\mathrm{W}}$ is the load of a compound in a water phase of an influent, Load $_{S}$ is the load of a compound in a primary sludge, $\mathrm{C}_{\mathrm{W}}$ is the concentration of antimicrobial in the WWTP influent (water phase) $\left(\mathrm{mg} / \mathrm{m}^{3}\right)$, Flow is the average daily flow rate in the WWTP $\left(\mathrm{m}^{3} / \mathrm{d}\right), \mathrm{C}_{\mathrm{S}}$ is the concentration of antimicrobial in the WWTP primary sludge $\left(\mathrm{mg} / \mathrm{m}^{3}\right)$, and PS is the average daily volume of the WWTP primary sludge $\left(\mathrm{m}^{3} / \mathrm{d}\right)$. 


\subsection{Statistical Analysis}

The statistical analysis of the results was performed with the STATISTICA version 13.1 for Windows (TIBCO Software Inc., Palo Alto, CA, USA) and Metaboanalyst 4.0. Student's t-test was used for comparison of samples. Principal components analysis (PCA) was used to determine differences between wastewater and sewage sludge.

\section{Conclusions}

In this study, $70 \%$ of the examined antimicrobials in both wastewater and sewage sludge collected from two Polish WWTPs were detected. To the best of our knowledge, this is the first report on antimicrobial occurrence in Polish WWTPs. The removal efficiency, antimicrobial resistance risk, and ecological threat (RQs) were examined according to the obtained data. The WWTPs removed $\sim 50 \%$ of selected antimicrobials with good efficiency, above $50 \%$. The level of antimicrobials in both untreated and treated wastewater, river as well as sewage sludge, poses a risk of resistance selection as shown by RQ calculations. Moreover, influents and river waters posed high and medium risk, particularly for cyanobacteria and eukaryotes due to the presence of ciprofloxacin, macrolides, and sulfamethoxazole. Following the obtained results, the watch list of substances for Union-wide monitoring in the field of water policy (already includes macrolides and ciprofloxacin) should be extended with sulfamethoxazole. Our study also indicates the need for evaluation of antimicrobials' concentrations not only in treated wastewater, but also in sewage sludge because of its usage in the fertilization process, which is environmentally sustainable options for re-use of the WWTP by-products. Several antimicrobials tested were present at levels that have been suggested to promote resistance development in sludge-amended soils (predicted concentrations).

The most important observation made is a possible pressure for the development of antimicrobial resistance in the WWTPs. WWTPs can be considered as potential hot spots for the dissemination of antimicrobial resistance. Leakage of antimicrobials can select for increased resistance among environmental bacteria and influence the virulence of antimicrobial-sensitive bacterial infections directly by reducing the infective dose and transmission $[27,29]$. Therefore, additional studies on the characterization of wastewater treatment plants' microbial communities and the profiles of antimicrobial-resistant genes are necessary. Our study also highlights the lack of sufficient data to evaluate or predict the risk of resistance development and environmental threat. In fact, data on risk assessment of wastewater and sludge in other European countries is also scarce.

Author Contributions: All authors contributed equally to the development of the manuscript in all aspects: Investigations and conceptualization, J.G., G.N.-J., D.K.; writing—original draft, J.G., G.N.-J., G.P.; writing一review and editing, J.G., G.N-J., E.K., M.H., G.P.; funding acquisition, G.P. and J.G. All authors have read and agreed to the published version of the manuscript.

Funding: This study was done under the project No 2017/26/M/NZ9/00071 funded by National Science Center, Poland. LC-MS/MS analyses were carried out with the use of the CePT infrastructure financed by the European Union, the European Regional Development Fund within the Operational Program "Innovative economy" for 2007-2013.

Acknowledgments: The authors would like to thank Marcin Giebułtowicz for drug sales data analysis and Ryszard Marszałek for his technical support during LC-MS/MS measurement. The authors are also very grateful to Bartosz Kózka and Bartłomiej Sankowski for their contribution in the conduct of the analytical study. We gratefully acknowledge the technical support provided by the WWTPs.

Conflicts of Interest: The authors declare no conflict of interest. 


\section{Appendix A}

Table A1. The comparison of the predicted (PLoad) and measured load of antimicrobial into WWTP1.

\begin{tabular}{|c|c|c|c|c|c|c|c|c|c|c|c|c|c|c|c|c|c|c|c|}
\hline & \multirow{2}{*}{$\begin{array}{c}\begin{array}{c}\text { Sale in } 2018 \\
\text { (kg/month) }\end{array} \\
\text { range } \\
\end{array}$} & \multicolumn{3}{|c|}{ PLoad $(\mathrm{g} / \mathrm{d})^{1}$} & \multicolumn{3}{|c|}{$\operatorname{Load}_{W}(\mathrm{~g} / \mathrm{d})^{2}$} & \multicolumn{3}{|c|}{$\operatorname{Load}_{S}(g / d)^{3}$} & \multicolumn{3}{|c|}{$\begin{array}{c}\text { Load }_{W} / \text { PLoad } \\
(\%)\end{array}$} & \multicolumn{3}{|c|}{$\begin{array}{c}\text { Load }_{\text {S/PLoad }} \\
(\%)\end{array}$} & \multicolumn{3}{|c|}{$\begin{array}{c}\operatorname{Load}_{W+S}{ }^{4} / \\
\text { PLoad(\%) }\end{array}$} \\
\hline & & $S^{5}$ & $\mathbf{A}$ & $\mathbf{W}$ & 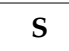 & A & $\mathbf{W}$ & $S$ & A & W & $S$ & A & W & $S$ & A & $\mathbf{W}$ & $\mathrm{S}$ & A & W \\
\hline $\mathrm{AZM}^{6}$ & $98-352$ & 25.3 & 26.3 & 47.2 & 0.3 & 4.8 & 1.9 & 0.2 & 2.9 & 5.4 & 1 & 13 & 4 & 1 & 8 & 11 & 2 & 21 & 15 \\
\hline CIP & $601-821$ & 106.5 & 128.9 & 112.8 & 58.7 & 15.6 & 27.1 & 54.2 & 26.1 & 60.1 & 55 & 12 & 24 & 51 & 20 & 53 & 106 & 32 & 77 \\
\hline CLR & 288-1509 & 68.9 & 121.1 & 145.5 & 7.9 & 11.2 & 19.4 & 0.04 & 0.27 & 0.09 & 12 & 9 & 13 & 0 & 0 & 0 & 12 & 9 & 13 \\
\hline CLI & $608-737$ & 109.9 & 116.4 & 106.8 & 1.6 & 2.4 & 6.8 & 0.3 & 0.2 & 0.8 & 1 & 2 & 6 & 0 & 0 & 1 & 1 & 2 & 7 \\
\hline NOR & 179-214 & 30.9 & 35.5 & 29.9 & 5.1 & 11.2 & 3.0 & 10.3 & 18.0 & 52.7 & 16 & 31 & 10 & 33 & 51 & 176 & 49 & 82 & 186 \\
\hline OFX & $609-829$ & 107.3 & 131.0 & 113.7 & 2.6 & 4.9 & 3.5 & 10.2 & 1.5 & 2.8 & 2 & 4 & 3 & 10 & 1 & 3 & 12 & 5 & 6 \\
\hline RIF & $40-48$ & 7.08 & 7.19 & 6.63 & 0.26 & 0.08 & 0.08 & & & & 4 & 1 & 1 & 0 & 0 & 0 & 4 & 1 & 1 \\
\hline ROX & 6-28 & 1.44 & 2.33 & 2.69 & 0.14 & 0.14 & 1.19 & & & & 10 & 6 & 44 & 0 & 0 & 0 & 10 & 6 & 44 \\
\hline SXT & $606-1358$ & 133.3 & 196.0 & 194.1 & 18.5 & 44.9 & 44.0 & 0.4 & 0.3 & 1.2 & 14 & 23 & 23 & 0 & 0 & 1 & 14 & 23 & 24 \\
\hline TMP & $122-272$ & 26.7 & 39.7 & 38.9 & 8.1 & 5.5 & 6.8 & 0.02 & 0.02 & 0.09 & 30 & 14 & 18 & 0 & 0 & 0 & 30 & 14 & 18 \\
\hline
\end{tabular}

1 PLoad predicted load of a compound calculated on the basis of sales data ${ }^{2} \mathrm{Load}_{\mathrm{W}}$ load of a compound calculated on the basis of measured concentration in a water phase of an influent

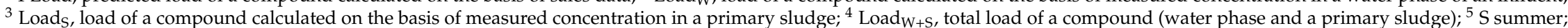
A, autumn; W, winter sampling. ${ }^{6}$ The pharmaceuticals used only in hospitals and frequently used in veterinary medicine were not presented 
Table A2. Mean values of sorption coefficients $\left(\log K_{d}\right)$ calculated for sludge and the percent of the total mass of the compound sorbed in sludge to its total daily mass load to WWTP.

\begin{tabular}{ccc}
\hline Antimicrobial & \% of Total Mass Load Sorbed to Sludge & $\log \mathbf{K}_{\mathbf{d}}$ Sludge \\
\hline AZM & $73 \%$ & $7.1 \pm 4.3$ \\
CIP & $55 \%$ & $7.3 \pm 4.2$ \\
CLR & $18 \%$ & $5.7 \pm 2.5$ \\
CLI & $9 \%$ & $5.7 \pm 2.6$ \\
LCM & $7 \%$ & $5.2 \pm 1.9$ \\
OFX & $43 \%$ & $7.7 \pm 4.8$ \\
OTC & $62 \%$ & $9.8 \pm 6.9$ \\
SDM & $32 \%$ & $6.8 \pm 3.4$ \\
SXT & $2 \%$ & $5.1 \pm 1.7$ \\
TET & $13 \%$ & $8.3 \pm 5.5$ \\
TBZ & $23 \%$ & $5.9 \pm 2.6$ \\
TMP & $19 \%$ & $4.8 \pm 1.6$ \\
VAN & $24 \%$ & $6.3 \pm 3.2$ \\
\hline
\end{tabular}

Table A3. Predicted antimicrobial concentration in sludge-amended soil (single sludge application).

\begin{tabular}{|c|c|c|c|c|c|c|c|c|c|c|}
\hline \multirow{2}{*}{$\begin{array}{l}\text { Antimicrobial } \\
(\mathrm{ng} / \mathrm{g})\end{array}$} & \multicolumn{2}{|c|}{ WWTP1-PS } & \multicolumn{2}{|c|}{ WWTP1-ES } & \multicolumn{2}{|c|}{ WWTP2-RS } & \multicolumn{2}{|c|}{ WWTP2-FS } & \multicolumn{2}{|c|}{ WWTP1-RS $^{1}$} \\
\hline & Mean & SD & Mean & SD & Mean & SD & Mean & SD & Mean & SD \\
\hline AZM & 1.9 & 1.3 & 0.55 & 0.50 & 0.17 & 0.14 & 2.3 & 1.6 & 0.14 & 0.13 \\
\hline CIP & 18 & 13 & 9.1 & 3.5 & 8.9 & 9.8 & 41 & 40 & 11.4 & 5.2 \\
\hline CLR & 0.42 & 0.09 & 0.03 & 0.02 & 0.03 & 0.04 & 0.33 & 0.37 & $<0.01$ & - \\
\hline CLI & 0.06 & 0.04 & 0.08 & 0.06 & 0.04 & 0.05 & 0.07 & 0.05 & 0.01 & 0.01 \\
\hline $\mathrm{LCM}$ & 0.01 & 0.01 & 0.01 & - & 0.01 & 0.01 & 0.03 & 0.04 & $<0.01$ & - \\
\hline NOR & 7.8 & 5.8 & 5.2 & 4.4 & 2.4 & 2.4 & 5.0 & 4.1 & - & - \\
\hline OFX & 1.2 & 1.6 & 0.94 & 0.91 & 0.44 & 0.33 & 0.70 & 0.21 & 0.05 & 0.02 \\
\hline OTC & 0.86 & 0.74 & 0.48 & 0.41 & 0.07 & 0.06 & 0.41 & 0.37 & 0.01 & 0.01 \\
\hline PEF & 0.36 & 0.25 & 0.28 & 0.20 & 0.28 & 0.22 & 0.38 & 0.15 & - & - \\
\hline ROX & 0.03 & - & $<0.01$ & - & $<0.01$ & - & $<0.01$ & - & $<0.01$ & - \\
\hline SD & $<0.01$ & & $<0.01$ & & $<0.01$ & - & 0.03 & - & $<0.01$ & - \\
\hline SDM & 0.03 & 0.03 & 0.03 & 0.03 & 0.03 & - & $<0.01$ & - & $<0.01$ & - \\
\hline SXT & $<0.03$ & - & 0.12 & 0.10 & $<0.03$ & - & $<0.03$ & - & 0.01 & 0.01 \\
\hline TET & 0.12 & 0.09 & 0.06 & 0.02 & 0.08 & 0.05 & 0.29 & 0.17 & 0.04 & 0.03 \\
\hline TBZ & 0.03 & 0.01 & 0.02 & 0.01 & 0.09 & 0.08 & 0.07 & 0.04 & 0.01 & 0.01 \\
\hline TMP & 0.25 & 0.19 & 0.01 & 0.01 & $<0.01$ & - & $<0.01$ & - & $<0.01$ & - \\
\hline VAN & 0.53 & 0.10 & 0.27 & 0.16 & 0.11 & - & $<0.01$ & - & 0.55 & 0.15 \\
\hline
\end{tabular}

${ }^{1}$ WWTP-PS, sludge after mechanical treatment; WWTP-ES, sludge after gravity treatment; WWTP-FS, sludge after an open fermentation pool; WWTP-RS, sludge for management.

Table A4. NOEC/EC 50 ( $\mu \mathrm{g} / \mathrm{L})$ and PNEC (ng/L) used for the risk assessment; nd, no data available. Abbreviations in parentheses indicate the most sensitive taxa: MA, microalgae; MP, macrophytes; IN, invertebrates. The data based on the review of Le Page [27].

\begin{tabular}{ccccc}
\hline Compound & $\begin{array}{c}\text { Cyanobacteria } \\
\text { NOEC/EC }_{\mathbf{5 0}}\end{array}$ & $\begin{array}{c}\text { Cyanobacteria } \\
\text { PNEC }\end{array}$ & $\begin{array}{c}\text { Eukaryote } \\
\text { NOEC/EC }\end{array}$ & $\begin{array}{c}\text { Eukaryote } \\
\text { PNEC }\end{array}$ \\
\hline AZM & 0.19 & 19 & 1.8 & $180(\mathrm{MA})$ \\
CIP & 5.65 & 565 & 10 & $1000(\mathrm{MP})$ \\
CLR & 0.84 & 84 & 2 & $40(\mathrm{MA})$ \\
ERY & 2 & 200 & 10.3 & $206(\mathrm{MA})$ \\
LCM & 18 & 1800 & 548 & $10976(\mathrm{MA})$ \\
MTZ & 0 & nd & 250,000 & $5000000(\mathrm{IN})$ \\
NOR & 1.6 & 160 & 300 & $3000(\mathrm{MP})$ \\
OFX & 5 & 500 & 31.2 & $624(\mathrm{MA})$ \\
OTC & 3.1 & 310 & 183 & $3660(\mathrm{MA})$ \\
ROX & nd & 390,000 & 10 & $100(\mathrm{MA})$ \\
SD & 3900 & 780,000 & 135 & $2700(\mathrm{MA})$ \\
SDM & 7800 & 590 & 100 & $5290(\mathrm{MA})$ \\
SXT & 5.9 & 9000 & 10 & $1000(\mathrm{MP}, \mathrm{IN})$ \\
TET & 90 & 135,800 & 300 & $6000(\mathrm{MP})$ \\
TMP & 1385 & 1000 & $20000(\mathrm{MP})$ \\
\hline
\end{tabular}


Table A5. Predicted no effect concentration values for resistance selection of microbial community in wastewater, sludge, and soil.

\begin{tabular}{cccc}
\hline Antimicrobial & $\begin{array}{c}\text { PNEC Wastewater } \\
\left(\mu \mathrm{g} / \mathbf{L}^{\mathbf{1}}\right.\end{array}$ & PNEC Sludge $(\boldsymbol{\mu g} / \mathbf{k g})^{\mathbf{2}}$ & ${\text { PNEC Soil }(\boldsymbol{\mu g} / \mathbf{k g})^{3}}^{\mathbf{3}}$ \\
\hline AZT & 0.25 & 1200 & 47 \\
CIP & 0.064 & 1200 & 27,000 \\
CLR & 0.25 & 140 & 66 \\
CLI & 1 & 280 & - \\
ER & 2 & - & 260 \\
LIN & 2 & 340 & - \\
METR & 0.125 & - & 0.07 \\
NFL & 0.5 & - & 300 \\
OFL & 0.5 & 4200 & 730 \\
OTET & 0.5 & $4,200,000$ & 210 \\
RIF & 0.5 & - & - \\
ROX & 1 & 4300 & 50 \\
STH & 16 & 2000 & 9.6 \\
TET & 1 & 3000 & 1100 \\
TRI & 0.5 & 100 & 3.7 \\
VAN & 8 & 17,000 & 2.4 \\
\hline
\end{tabular}

${ }^{1}$ According to Bengtsson-Palme and Larsson [28]; ${ }^{2}$ calculated based on $\mathrm{K}_{\mathrm{d}}$ obtained for sludge; ${ }^{3}$ calculated according to $[26,40,42,62]$.

\section{References}

1. $\mathrm{Fu}, \mathrm{W} . ; \mathrm{Fu}, \mathrm{J} . ; \mathrm{Li}, \mathrm{X}$; Li, B.; Wang, X. Occurrence and fate of PPCPs in typical drinking water treatment plants in China. Environ. Geochem Health 2019, 41, 5-15. [CrossRef] [PubMed]

2. Omar, T.F.T.; Aris, A.Z.; Yusoff, F.M.; Mustafa, S. Risk assessment of pharmaceutically active compounds (PhACs) in the Klang River estuary, Malaysia. Environ. Geochem Health 2019, 41, 211-223. [CrossRef] [PubMed]

3. Zhang, P.; Zhou, H.; Li, K.; Zhao, X.; Liu, Q.; Li, D.; Zhao, G. Occurrence of pharmaceuticals and personal care products, and their associated environmental risks in a large shallow lake in north China. Environ. Geochem. Health 2018, 40, 1525-1539. [CrossRef] [PubMed]

4. Chen, C.; Li, J.; Chen, P.; Ding, R.; Zhang, P.; Li, X. Occurrence of antibiotics and antibiotic resistances in soils from wastewater irrigation areas in Beijing and Tianjin, China. Environ. Pollut. 2014, 193, 94-101. [CrossRef]

5. Rodriguez-Mozaz, S.; Chamorro, S.; Marti, E.; Huerta, B.; Gros, M.; Sanchez-Melsio, A.; Borrego, C.M.; Barcelo, D.; Balcazar, J.L. Occurrence of antibiotics and antibiotic resistance genes in hospital and urban wastewaters and their impact on the receiving river. Water Res. 2015, 69, 234-242. [CrossRef]

6. Harrabi, M.; Varela Della Giustina, S.; Aloulou, F.; Rodriguez-Mozaz, S.; Barceló, D.; Elleuch, B. Analysis of multiclass antibiotic residues in urban wastewater in Tunisia. Environ. Nanotechnol. Monit. Manag. 2018, 10, 163-170. [CrossRef]

7. Dinh, Q.; Moreau-Guigon, E.; Labadie, P.; Alliot, F.; Teil, M.J.; Blanchard, M.; Eurin, J.; Chevreuil, M. Fate of antibiotics from hospital and domestic sources in a sewage network. Sci. Total Environ. 2017, 575, 758-766. [CrossRef]

8. Marx, C.; Gunther, N.; Schubert, S.; Oertel, R.; Ahnert, M.; Krebs, P.; Kuehn, V. Mass flow of antibiotics in a wastewater treatment plant focusing on removal variations due to operational parameters. Sci. Total Environ. 2015, 538, 779-788. [CrossRef]

9. Stadler, L.B.; Delgado Vela, J.; Jain, S.; Dick, G.J.; Love, N.G. Elucidating the impact of microbial community biodiversity on pharmaceutical biotransformation during wastewater treatment. Microb. Biotechnol. 2018, 11, 995-1007. [CrossRef]

10. Luo, Y.; Guo, W.; Ngo, H.H.; Nghiem, L.D.; Hai, F.I.; Zhang, J.; Liang, S.; Wang, X.C. A review on the occurrence of micropollutants in the aquatic environment and their fate and removal during wastewater treatment. Sci. Total Environ. 2014, 473-474, 619-641. [CrossRef] 
11. ECDC. European Centre for Disease Prevention and Control (2016) An agency of the European Union. Available online: https://www.ecdc.europa.eu/en (accessed on 3 October 2019).

12. Krzeminski, P.; Tomei, M.C.; Karaolia, P.; Langenhoff, A.; Almeida, C.M.R.; Felis, E.; Gritten, F.; Andersen, H.R.; Fernandes, T.; Manaia, C.M.; et al. Performance of secondary wastewater treatment methods for the removal of contaminants of emerging concern implicated in crop uptake and antibiotic resistance spread: A review. Sci. Total Environ. 2019, 648, 1052-1081. [CrossRef] [PubMed]

13. Mompelat, S.; Le Bot, B.; Thomas, O. Occurrence and fate of pharmaceutical products and by-products, from resource to drinking water. Environ. Int. 2009, 35, 803-814. [CrossRef]

14. Grenni, P.; Ancona, V.; Barra Caracciolo, A. Ecological effects of antibiotics on natural ecosystems: A review. Microchem. J. 2018, 136, 25-39. [CrossRef]

15. Zhao, S.; Liu, X.; Cheng, D.; Liu, G.; Liang, B.; Cui, B.; Bai, J. Temporal-spatial variation and partitioning prediction of antibiotics in surface water and sediments from the intertidal zones of the Yellow River Delta, China. Sci. Total Environ. 2016, 569-570, 1350-1358. [CrossRef]

16. Watkinson, A.J.; Murby, E.J.; Kolpin, D.W.; Costanzo, S.D. The occurrence of antibiotics in an urban watershed: From wastewater to drinking water. Sci. Total Environ. 2009, 407, 2711-2723. [CrossRef]

17. Loraine, G.A.; Pettigrove, M.E. Seasonal Variations in Concentrations of Pharmaceuticals and Personal Care Products in Drinking Water and Reclaimed Wastewater in Southern California. Environ. Sci. Technol. 2006, 40, 687-695. [CrossRef]

18. Giebultowicz, J.; Tyski, S.; Wolinowska, R.; Grzybowska, W.; Zareba, T.; Drobniewska, A.; Wroczynski, P.; Nalecz-Jawecki, G. Occurrence of antimicrobial agents, drug-resistant bacteria, and genes in the sewage-impacted Vistula River (Poland). Environ. Sci. Pollut. Res. Int. 2018, 25, 5788-5807. [CrossRef]

19. Kümmerer, K.; Henninger, A. Promoting resistance by the emission of antibiotics from hospitals and households into effluent. Clin. Microbiol. Infect. 2003, 9, 1203-1214. [CrossRef]

20. Senta, I.; Terzic, S.; Ahel, M. Occurrence and fate of dissolved and particulate antimicrobials in municipal wastewater treatment. Water Res. 2013, 47, 705-714. [CrossRef]

21. Radjenovic, J.; Petrovic, M.; Barcelo, D. Fate and distribution of pharmaceuticals in wastewater and sewage sludge of the conventional activated sludge (CAS) and advanced membrane bioreactor (MBR) treatment. Water Res. 2009, 43, 831-841. [CrossRef]

22. Wang, S.; Cui, Y.; Li, A.; Zhang, W.; Wang, D.; Ma, J. Fate of antibiotics in three distinct sludge treatment wetlands under different operating conditions. Sci Total Environ. 2019, 671, 443-451. [CrossRef] [PubMed]

23. Gobel, A.; McArdell, C.S.; Joss, A.; Siegrist, H.; Giger, W. Fate of sulfonamides, macrolides, and trimethoprim in different wastewater treatment technologies. Sci. Total Environ. 2007, 372, 361-371. [CrossRef] [PubMed]

24. Ostman, M.; Lindberg, R.H.; Fick, J.; Bjorn, E.; Tysklind, M. Screening of biocides, metals and antibiotics in Swedish sewage sludge and wastewater. Water Res. 2017, 115, 318-328. [CrossRef] [PubMed]

25. Plosz, B.G.; Leknes, H.; Liltved, H.; Thomas, K.V. Diurnal variations in the occurrence and the fate of hormones and antibiotics in activated sludge wastewater treatment in Oslo, Norway. Sci Total Environ. 2010, 408, 1915-1924. [CrossRef]

26. Cycon, M.; Mrozik, A.; Piotrowska-Seget, Z. Antibiotics in the Soil Environment-Degradation and Their Impact on Microbial Activity and Diversity. Front. Microbiol. 2019, 10, 338. [CrossRef]

27. Le Page, G.; Gunnarsson, L.; Snape, J.; Tyler, C.R. Integrating human and environmental health in antibiotic risk assessment: A critical analysis of protection goals, species sensitivity and antimicrobial resistance. Environ. Int. 2017, 109, 155-169. [CrossRef]

28. Bengtsson-Palme, J.; Larsson, D.G.J. Concentrations of antibiotics predicted to select for resistant bacteria: Proposed limits for environmental regulation. Environ. Int. 2016, 86, 140-149. [CrossRef]

29. O'Neill, J. Tackling drug-resistant infections globally:final report and recommendations. Rev. Antimicrob. Resist. 2016. Available online: https://amr-review.org/sites/default/files/160518_Final\%20paper_with\% 20cover.pdf (accessed on 21 February 2020).

30. Wishart, D.S.; Feunang, Y.D.; Guo, A.C.; Lo, E.J.; Marcu, A.; Grant, J.R.; Sajed, T.; Johnson, D.; Li, C.; Sayeeda, Z.; et al. DrugBank 5.0: A major update to the DrugBank database for 2018. Nucleic Acids Res. 2018, 46, D1074-D1082. [CrossRef]

31. Zachara, J.; Zachara, R.; Zachara, N.; Matuszczak, A.; Kłoda, K. The comparison of use of antibiotics due to acute respiratory infections in the rural population of primary care in 2010 and 2017. J. Educ. Health Sport $2019,9,70-83$. 
32. Watkinson, A.J.; Murby, E.J.; Costanzo, S.D. Removal of antibiotics in conventional and advanced wastewater treatment: Implications for environmental discharge and wastewater recycling. Water Res. 2007, 41, 4164-4176. [CrossRef] [PubMed]

33. Verlicchi, P.; Al Aukidy, M.; Zambello, E. Occurrence of pharmaceutical compounds in urban wastewater: Removal, mass load and environmental risk after a secondary treatment-a review. Sci Total Environ. 2012, 429, 123-155. [CrossRef] [PubMed]

34. Peng, X.; Wang, Z.; Kuang, W.; Tan, J.; Li, K. A preliminary study on the occurrence and behavior of sulfonamides, ofloxacin and chloramphenicol antimicrobials in wastewaters of two sewage treatment plants in Guangzhou, China. Sci Total Environ. 2006, 371, 314-322. [CrossRef] [PubMed]

35. Cunha, B.A. Vancomycin revisited: A reappraisal of clinical use. Crit. Care Clin. 2008, 24, 393-420. [CrossRef]

36. Göbel, A.; Thomsen, A.; McArdell, C.S.; Joss, A.; Giger, W. Occurrence and Sorption Behavior of Sulfonamides, Macrolides, and Trimethoprim in Activated Sludge Treatment. Environ. Sci. Technol. 2005, 39, 3981-3989. [CrossRef]

37. Le-Minh, N.; Khan, S.J.; Drewes, J.E.; Stuetz, R.M. Fate of antibiotics during municipal water recycling treatment processes. Water Res. 2010, 44, 4295-4323. [CrossRef]

38. Choi, K.J.; Kim, S.G.; Kim, S.H. Removal of tetracycline and sulfonamide classes of antibiotic compound by powdered activated carbon. Environ. Technol. 2008, 29, 333-342. [CrossRef]

39. Brown, K.D.; Kulis, J.; Thomson, B.; Chapman, T.H.; Mawhinney, D.B. Occurrence of antibiotics in hospital, residential, and dairy effluent, municipal wastewater, and the Rio Grande in New Mexico. Sci. Total Environ. 2006, 366, 772-783. [CrossRef]

40. Sidhu, H.; D'Angelo, E.; O'Connor, G. Retention-release of ciprofloxacin and azithromycin in biosolids and biosolids-amended soils. Sci. Total Environ. 2019, 650, 173-183. [CrossRef]

41. Kaeseberg, T.; Zhang, J.; Schubert, S.; Oertel, R.; Siedel, H.; Krebs, P. Sewer sediment-bound antibiotics as a potential environmental risk: Adsorption and desorption affinity of 14 antibiotics and one metabolite. Environ. Pollut. 2018, 239, 638-647. [CrossRef]

42. Wu, C.; Spongberg, A.L.; Witter, J.D. Sorption and biodegradation of selected antibiotics in biosolids. J. Environ. Sci Health A 2009, 44, 454-461. [CrossRef] [PubMed]

43. Wang, L.; Qiang, Z.; Li, Y.; Ben, W. An insight into the removal of fluoroquinolones in activated sludge process: Sorption and biodegradation characteristics. J. Environ. Sci (China) 2017, 56, 263-271. [CrossRef] [PubMed]

44. Wang, W.; Zhang, W.; Liang, H.; Gao, D. Occurrence and fate of typical antibiotics in wastewater treatment plants in Harbin, North-east China. Front. Environ. Sci. Eng. 2019, 13, 34. [CrossRef]

45. Rodayan, A.; Majewsky, M.; Yargeau, V. Impact of approach used to determine removal levels of drugs of abuse during wastewater treatment. Sci. Total Environ. 2014, 487, 731-739. [CrossRef]

46. Golet, E.M.; Alder, A.C.; Giger, W. Environmental Exposure and Risk Assessment of Fluoroquinolone Antibacterial Agents in Wastewater and River Water of the Glatt Valley Watershed, Switzerland. Environ. Sci. Technol. 2002, 36, 3645-3651. [CrossRef]

47. Gao, L.; Shi, Y.; Li, W.; Niu, H.; Liu, J.; Cai, Y. Occurrence of antibiotics in eight sewage treatment plants in Beijing, China. Chemosphere 2012, 86, 665-671. [CrossRef]

48. Roberts, P.H.; Thomas, K.V. The occurrence of selected pharmaceuticals in wastewater effluent and surface waters of the lower Tyne catchment. Sci. Total Environ. 2006, 356, 143-153. [CrossRef]

49. Chunhui, Z.; Liangliang, W.; Xiangyu, G.; Xudan, H. Antibiotics in WWTP discharge into the Chaobai River, Beijing. Arch. Environ. Prot. 2016, 42, 48-57. [CrossRef]

50. Gros, M.; Petrovic, M.; Ginebreda, A.; Barcelo, D. Removal of pharmaceuticals during wastewater treatment and environmental risk assessment using hazard indexes. Environ. Int. 2010, 36, 15-26. [CrossRef]

51. Kummerer, K. The presence of pharmaceuticals in the environment due to human use-present knowledge and future challenges. J. Environ. Manag. 2009, 90, 2354-2366. [CrossRef]

52. Osorio, V.; Larrañaga, A.; Aceña, J.; Pérez, S.; Barceló, D. Concentration and risk of pharmaceuticals in freshwater systems are related to the population density and the livestock units in Iberian Rivers. Sci. Total Environ. 2016, 540, 267-277. [CrossRef] [PubMed]

53. Cheng, M.; Wu, L.; Huang, Y.; Luo, Y.; Christie, P. Total concentrations of heavy metals and occurrence of antibiotics in sewage sludges from cities throughout China. J. Soils Sediments 2014, 14, 1123-1135. [CrossRef] 
54. Lindberg, R.H.; Wennberg, P.; Johansson, M.I.; Tysklind, M.; Andersson, B.A.V. Screening of Human Antibiotic Substances and Determination of Weekly Mass Flows in Five Sewage Treatment Plants in Sweden. Environ. Sci. Technol. 2005, 39, 3421-3429. [CrossRef] [PubMed]

55. Golet, E.M.; Xifra, I.; Siegrist, H.; Alder, A.C.; Giger, W. Environmental Exposure Assessment of Fluoroquinolone Antibacterial Agents from Sewage to Soil. Environ. Sci. Technol. 2003, 37, 3243-3249. [CrossRef]

56. Göbel, A.; Thomsen, A.; McArdell, C.S.; Alder, A.C.; Giger, W.; Theiß, N.; Löffler, D.; Ternes, T.A. Extraction and determination of sulfonamides, macrolides, and trimethoprim in sewage sludge. J. Chromatogr. A 2005, 1085, 179-189. [CrossRef]

57. GUS. Statistical Yearbook of the Regions_Poland; Statistics Poland: Warsaw, Poland, 2018.

58. Buta, M.; Hubeny, J.; Zieliński, W.; Korzeniewska, E.; Harnisz, M.; Nowrotek, M.; Płaza, G. The Occurrence of Integrase Genes in Different Stages of Wastewater Treatment. J. Ecol. Eng. 2019, 20, 39-45. [CrossRef]

59. Douziech, M.; Conesa, I.R.; Benítez-López, A.; Franco, A.; Huijbregts, M.; van Zelm, R. Quantifying variability in removal efficiencies of chemicals in activated sludge wastewater treatment plants-a meta-analytical approach. Environ. Sci. Processes Impacts 2018, 20, 171-182. [CrossRef]

60. ECHA. Guidance on information requirements and chemical safety assessment; European Chemicals Agency: Helsinki, Finland, 2008.

61. Ben, W.; Zhu, B.; Yuan, X.; Zhang, Y.; Yang, M.; Qiang, Z. Occurrence, removal and risk of organic micropollutants in wastewater treatment plants across China: Comparison of wastewater treatment processes. Water Res. 2018, 130, 38-46. [CrossRef]

62. Rabùlle, M.; Spliid, N.H. Sorption and mobility of metronidazole, olaquindox, oxytetracycline and tylosin in soil. Chemosphere 2000, 40, 8. [CrossRef]

Sample Availability: Samples of the compounds are not available from the authors.

(C) 2020 by the authors. Licensee MDPI, Basel, Switzerland. This article is an open access article distributed under the terms and conditions of the Creative Commons Attribution (CC BY) license (http://creativecommons.org/licenses/by/4.0/). 